\title{
DESARROLLO DE BANCO DE HONGOS COMESTIBLES INSTITUTO FORESTAL
}

\author{
Chung, Patricio ${ }^{1}$
}

\section{RESUMEN}

Es ampliamente reconocido que los bosques no solo producen madera, sino que también numerosos otros productos forestales no madereros (PFNM), con frecuencia de sorprendente e insospechado valor económico.

Los hongos comestibles presentes en los bosques de Chile constituyen un recurso valioso, cuyo comercio adquiere cada vez mayor importancia. No obstante, su producción natural en el bosque es variable, de modo que el interés por obtener una producción alta y estable ha motivado iniciativas para cultivarlos mediante el establecimiento de plantas inoculadas con las especies y cepas de mayor valor. La relación simbiótica que se establece entre hongos y especies forestales constituye una ventajosa oportunidad para implementar líneas de investigación y desarrollo innovativo, que conjuguen la recuperación de suelos degradados, la restauración y enriquecimiento de los bosques nativos y el mejor desempeño de las plantaciones, con la generación de productos intermedios de alto valor económico, ecológico y social, como son los hongos micorrícicos comestibles.

Dentro de las líneas de trabajo del Instituto Forestal en esta materia se ha estado estableciendo un banco de hongos comestibles. Esto mediante colectas de especies y cepas de hongos silvestres comestibles asociados a bosques nativos y bosques plantados en las regiones de Maule y Bio Bio. Establecido este banco, se continuará con líneas de trabajo orientadas a definir protocolos que lleven a una producción sostenida de hongos silvestres comestibles en ambientes silvestres. Considerando ambas regiones se colectó un total de 95 cepas desde bosques nativos y plantaciones, 65 de las cuales corresponden a hongos comestibles.

Palabras clave: PFNM, Bosque nativo, Plantaciones Forestales, Hongos comestibles.

\section{SUMMARY}

Well known is today that forest produce not only Wood but also a number of other non wood forest products (NWFP) which very often have a high and unexpected value. Mushrooms present in Chilean forests are a valuable resource and its trade is becoming an important one. However, its natural production in the forests is very variable and the interest for obtaining high and sustainable productions has driven initiatives to improve that through the establishment of inoculated seedlings in the forests with the higher value species and strains. The symbiotic relationship between fungus and forest trees represents a favourable opportunity for carrying out research and innovative developing lines joining degraded soils recover, native forest restoration and enrichment and a better planted forest growth, to the generation of intermediate high value products of economical, social and environmental importance, represented by the mushrooms.

Within the Chilean Forestry Institute research lines on the matter a fungus bank is being established through edible fungus and strains collect in native and planted forests located in the Maule and Bio Bio regions. Once established the bank, new research lines will be carried out to define technical the protocols to obtain a sustainable mushrooms production in the Chilean forests. So far, considering both regions, Maule and Bio Bio, and native and planted forests, a total of 95 strains has been collected, 65 of which are mushrooms.

Key words: NWFP, Native Forests, Planted forests, Mushrooms

\footnotetext{
${ }^{1}$ Ingeniero Forestal, Investigador Sede Bio Bio, Concepción. Instituto Forestal pchung@infor.cl
} 


\section{INTRODUCCIÓN}

La producción de hongos comestibles en bosques y matorrales constituye una interesante alternativa de ingresos, aunque con frecuencia es ignorada o poco valorada. En general, al mencionar los productos forestales, se piensa exclusivamente en la madera, en circunstancias que los Productos Forestales No Madereros (PFNM), particularmente los hongos comestibles, ofrecen también una valiosa oportunidad productiva para propietarios y recolectores.

La producción de hongos comestibles puede generar una rentabilidad incluso superior a la de cualquier otro producto forestal, sea madera, corteza o frutos, en especial en sitios en que la irregularidad climática y la degradación de los suelos no permite un rendimiento maderero elevado, tal como ocurre en muchos bosques naturales en Chile.

Las rentas obtenidas por la explotación de bosques son logradas en lapsos de tiempo bastante largos, lo que a menudo genera un desarraigo de las comunidades rurales. Lograr que estas comunidades se identifiquen con el bosque puede contribuir a solucionar problemas como el despoblamiento rural, la frecuencia de incendios y otros. Involucrar a la comunidad en el manejo y cuidado del bosque permite que esta lo perciba como un recurso que es necesario conservar. Esta identidad solo se puede lograr si la comunidad rural ve en el bosque algo productivo, que le reporte beneficios periódicamente.

Los hongos silvestres comestibles pueden generar un flujo de ingresos adicionales durante todo el período de rotación de un cultivo forestal, haciendo más atractiva la inversión en silvicultura. Los hongos por sí solos ya son importantes para la generación de ingresos estacionales y también como fuente de alimentos para los habitantes de zonas rurales, por cuanto constituyen un producto altamente proteico, con abundante fibra, vitaminas, minerales y escasa cantidad de grasas y colesterol.

Los hongos comestibles presentes en los bosques de Chile constituyen un recurso valioso, cuyo comercio adquiere cada vez mayor importancia. No obstante, su producción natural en el bosque es variable, de modo que el interés por obtener una producción alta y estable ha motivado iniciativas para cultivarlos mediante el establecimiento de plantas inoculadas con las especies y cepas de mayor valor.

En general, la producción de hongos no suele ser considera como un objetivo productivo al momento de establecer plantaciones forestales. Esto se debe a la dificultad que involucra cuantificar su producción y su efecto sobre la rentabilidad final para el propietario. Para superar estas dificultades se requieren estudios específicos, así como también crear pautas de gestión de los bosques que permitan compatibilizar el aprovechamiento de los hongos con las restantes finalidades del bosque.

Uno de los factores que explica la relativamente baja producción de cuerpos frutales de hongos comestibles en los bosques naturales y plantaciones forestales es el empleo de técnicas de establecimiento y/o manejo inadecuadas, que afectan negativamente las condiciones ambientales al interior de los bosques, limitando la producción de hongos durante el desarrollo de las masas boscosas.

De igual forma, la falta de información y conocimientos respecto de los hongos comestibles y sus asociaciones con especies forestales limita el aprovechamiento de estos organismos y también las ventajas productivas de estas asociaciones para las plantas.

La relación simbiótica que se establece entre hongos y especies forestales constituye una ventajosa oportunidad para implementar líneas de investigación y desarrollo innovativo, que conjuguen la recuperación de suelos degradados, la restauración y enriquecimiento del bosque nativo, y el mejor desempeño de las plantaciones, con la generación de productos intermedios de alto valor económico, ecológico y social, como son los hongos micorrícicos comestibles. 
Esta iniciativa, enmarcada en el área de investigación de Silvicultura y Manejo de Ecosistemas Forestales Nativos y Exóticos del Instituto Forestal, dentro de la cual se inserta la línea investigación sobre Productos Forestales No Madereros (PFNM), tiene como objetivo principal establecer un banco de hongos comestibles mediante la realización de prospecciones y colectas de especies y cepas de hongos silvestres comestibles asociados a bosques de Nothofagus spp y a plantaciones de Pinus radiata en las regiones de Maule y Bio Bio. Una vez obtenido dicho material, se establecerán líneas de investigaciones en torno a la búsqueda de protocolos que lleven a una producción sostenida de hongos silvestres comestibles en ambientes silvestres.

\section{ANTECEDENTES}

Es ampliamente reconocido que los bosques no solo producen madera, sino que también numerosos otros productos forestales no madereros (PFNM), con frecuencia de sorprendente e insospechado valor económico. Los PFNM son "todos aquellos productos biológicos, excluida la madera, leña y carbón, que son extraídos de los bosques naturales para el uso humano" (Peters, 1996).

Catalán (2006) estima que los PFNM pueden constituir hasta el 30 o $40 \%$ del uso comercial de un bosque. Su importancia radica en que constituyen una fuente de ingresos para sus recolectores y en que potencialmente pueden transformarse en la clave para el manejo sustentable de los bosques nativos.

La recolección periódica de productos del bosque representa un ingreso complementario en la economía de muchas familias rurales. La característica estacional de la producción permite mantener en algunos hogares una actividad casi continua que se reparte entre sucesivos productos, constituyendo además una gran oportunidad para valorizar el bosque nativo a través de la generación de actividades económicas alternativas que permiten a los pequeños propietarios ocupar su excedente de mano de obra, obtener ingresos estables y diversificar su base productiva (Tacón y Palma, 2005).

Aunque no existen registros del mercado interno de estos productos, que permitan evaluar su importancia económica en el ámbito nacional, se dispone de estadísticas de comercialización para la mayor parte de los productos de exportación y se aprecia que la mayor demanda se concentra en los países desarrollados del hemisferio norte, los cuales importan principalmente materias primas para la industria farmacéutica, cosmética y alimentaria.

El mercado internacional de los PFNM es creciente y con amplias posibilidades para el futuro (INFOR, 2004; Tacón y Palma, 2005).

A pesar del sorprendente y atractivo negocio que resulta ser la exportación de PFNM, no se encuentra exento de problemas, los elevados precios de compra de ellos han generado una enorme presión por su extracción, lo que ha significado la desaparición de muchas de sus poblaciones naturales, debido principalmente a sus métodos de extracción (Tacón y Palma, 2005).

Este es el caso de algunas especies de hongos silvestres comestibles presentes en los bosques nativos chilenos, cuya sobreutilización está implicando una disminución cualitativa y cuantitativa del recurso. Se extrae la totalidad de los ejemplares comprometiendo así su aprovechamiento sostenible en el tiempo, llegando incluso a la destrucción de los bosques que los albergan, como ocurre en el caso del hongo morcella.

Entre las especies nativas más perjudicadas, están algunas como Boletus loyo, Cortinarius lebre y varias especies de los géneros Ramaria, Morchella y Cyttaria, son recolectadas por habitantes de zonas rurales para su consumo y/o venta.

Para muchos recolectores los hongos nativos son una de sus principales fuentes de ingresos, tienen alta demanda y elevados precios, pero son cada vez más escasos, lo que motiva 
que muchas familias se dediquen a su recolección en las regiones de Bio Bio y La Araucanía (Taller de Acción Cultural, 2003).

La situación descrita justifica plenamente la implementación de acciones orientadas a aumentar la presencia de las distintas especies de hongos comestibles en los bosques nativos, medida necesaria para que el negocio no se transforme en un agente de degradación, sino que al contrario sea un incentivo para su manejo forestal sustentable.

Es así como en los últimos años los productos forestales no madereros del bosque nativo han concentrado la atención de diversos profesionales, debido a la oportunidad que se presenta para la conservación de la biodiversidad, el desarrollo sustentable y la obtención de beneficios económicos por los altos niveles de comercialización que han alcanzado a escala global diversos productos (Saavedra, 2004).

En el caso de las plantaciones de pino en tanto, existen importantes especies de hongos comestibles que son colectadas y comercializadas a nivel nacional e internacional. Su presencia se ve incrementada a edades de entre los 4 y 12 años, siendo las especies fúngicas típicas de estas masas vegetacionales Suillus luteus, $S$. granulatus y Lactarius deliciosus.

\section{MATERIAL Y MÉTODO}

\section{Etapas del Trabajo}

El trabajo se dividió en varias etapas, comenzando con la identificación de los hábitats naturales en donde se desarrollan los hongos comestibles, siguiendo con la prospección y colecta de especímenes, y la toma de datos de las características ambientales en las cuales se desarrollan los cuerpos fructíferos.

Los hongos fueron identificados y fotografiados, se los codificó y posteriormente cada ejemplar colectado fue aislado in vitro bajo un medio nutritivo estéril. Finalmente se efectuaron ensayos para definir el o los medios de cultivo más aptos para el desarrollo de cada cepa colectada y aislada.

Posteriormente el material se incorporó al cepario del Instituto Forestal, formando parte del material fúngico con potencialidades alimenticias para trabajos de investigación orientados a incluir estos organismos en la silvicultura de bosques y plantaciones.

\section{Áreas Potenciales de Colecta}

La información utilizada para establecer las posibles áreas de prospección y colecta de especímenes de hongos comestibles se basó en la ubicación de las masas vegetacionales con las cuales se asocian las distintas especies de hongos, tanto nativas como exóticas.

Estos hongos se ven favorecidos con la presencia de especies del género Nothofagus, como N. obliqua (roble), N. alpina (raulí), N. dombeyi (coihue), N. glauca (hualo) y N. Alessandri (ruil), como también por las plantaciones de Pinus radiata. Las áreas de prospección se determinaron de acuerdo a dos fuentes de información:

Catastro de los Recursos Vegetacionales Nativos de Chile, actualizado para las regiones de Maule y del Bio Bio en los años 2009 y 2008, respectivamente (CONAF, 1997).

Para la elaboración del mapa se identificaron masas vegetacionales con presencia de especies del género Nothofagus, en base a criterios de dominancia de las mismas. En los mapas confeccionados para las regiones de Maule y Bio Bio, se ubicaron formaciones con presencia de roble, raulí, coihue, hualo y ruil (este último, solo presente en la región de Maule) en condición de especies dominantes o codominantes (Anexo $N^{\circ} 1$ ). 
- Para Pinus radiata, se utilizó el Mapa de Zonas de Crecimiento del Modelo Nacional de Simulación de Crecimiento de esta especie, el cual define una zonificación basada en características de clima, suelo y rendimiento, entre otras variables. Se emplearon los mapas para las regiones del Maule y Bio Bio (Anexo N 1) (Real, 1990).

\section{Prospección y Colecta}

Confeccionados los mapas con las áreas potenciales de prospección y posterior colecta del material fúngico, se prepararon formularios de terreno para registrar las descripciones geográficas y ambientales de los sitios de colecta de cada una de las cepas. Además, se estableció una metodología para realizar las campañas de prospección y colecta del material fúngico.

Para cada muestra colectada se completó una ficha que recoge en forma simple la mayor información posible de las características ambientales del sitio de crecimiento del espécimen colectado, destacándose información como ubicación geográfica, asociación vegetacional, suelo, altitud y exposición, entre otros antecedentes. Se contó con un GPS para establecer la ubicación geográfica.

Se complemento esto en laboratorio posteriormente con un registro fotográfico del material y la digitación de los antecedentes ambientales, conformando un registro computacional. Mediante un código de identificación, se vinculará la información anterior con cada cultivo dentro del banco de hongos comestibles creado dentro del Laboratorio de Micología de la Sede Bio Bio del Instituto Forestal.

\section{Campaña de Terreno}

En el país existen dos épocas de cosecha de hongos; otoño y primavera, las cuales son muy notorias para las regiones de Maule y Bio Bio. Además, los períodos de aparición de los hongos pueden variar de un año a otro debido a que están muy ligados a factores climáticos.

Los parámetros principales que inciden en esto son la temperatura y las precipitaciones, por lo que no es posible precisar una fecha de aparición y término de una producción fúngica determinada.

Si bien se identificaron las zonas vegetacionales en donde se desarrollaban las especies Pinus radiata y Nothofagus spp, la colecta se desarrolló en base a las condiciones de humedad existentes en las regiones de prospección.

La escasa humedad existente en las áreas de colecta producto del atraso de las lluvias, obligó a desarrollar las actividades iniciales de prospección y colecta de material en las zonas cercanas a la costa, aumentando así las posibilidades de encontrar especímenes de hongos.

En el transcurso de los meses se ampliaron las zonas de búsqueda, debido al aumento de las lluvias y con ello de la aparición de los hongos comestibles silvestres, comenzando las distintas especies a aparecer en concordancia con su fenología reproductiva.

Para el año de colecta la época de lluvias y de condiciones favorables para la fructificación de los hongos se amplió hasta llegar a noviembre, e incluso principios de diciembre. Un ejemplo de ello fueron las especies del género Morchella, para las que se amplió el período de fructificación en varias zonas del país.

Existen marcados períodos de aparición de una u otra especie de hongo comestible silvestre dependiendo de su ciclo. Por ejemplo, Boletus loyo comienza a aparecer a fines de febrero y comienzos de marzo con las primeras lluvias de otoño y su fructificación solo dura hasta el mes de mayo, mientras que para el género Morchella las fructificaciones solo ocurren entre septiembre y mediados de noviembre. 
El comienzo de los trabajos de prospección y colecta fue 15 días después de las primeras lluvias otoñales de carácter abundante, que permitieran humedecer la capa vegetal y el primer horizonte del suelo.

La colecta se realizó de acuerdo al siguiente protocolo:

a. Selección priorizada de sitios de colecta en función de características climáticas favorables a la fructificación.

b. Identificación preliminar de los hongos en terreno y captura de datos para la caracterización del lugar de muestreo.

c. Extracción de cuerpos fructíferos y limpieza de los mismos con brocha o pincel grueso para eliminar partículas de suelo y materia orgánica.

d. Embalaje de las muestras en bolsas de papel para permitir la respiración del hongo e impedir la acumulación de humedad, lo que induciría a un mayor deterioro de la muestra.

f. Identificación de la bolsa con el número de la muestra colectada en terreno, lugar y fecha.

g. Almacenaje en contenedor de aislapol o plástico con hielo o ice pack para su preservación durante el viaje.

h. Transporte en forma rápida (no más de 2 días) al laboratorio para proceder a la aislación del micelio o esporas.

i. Identificación final si fuese necesario, tanto del cuerpo frutal como del micelio aislado con el apoyo de un especialista en taxonomía fúngica. En esta actividad se contó con la ayuda del Dr. Götz Palfner de la Facultad de Ciencias Naturales y Oceanográficas de la Universidad de Concepción.

\section{Aislación y Acondicionamiento de Cepas}

\section{- Codificación}

Con el fin de ordenar los especímenes colectados, aislados e incorporados al Cepario de Hongos Comestibles del Instituto Forestal, se utilizó una codificación que permitió vincular la información de terreno con las diferentes cepas aisladas. El código aplicado fue el siguiente:

\section{IFAABBCCC}

Donde: IF: Instituto Forestal (Institución Colectora)

AA: $\quad$ Región de Chile

BB: $\quad$ Sector de Colecta

CCC: $\quad$ Número de la cepa

\section{- Confección de Medios de Cultivo}

Para conseguir la aislación definitiva se preparó un medio de cultivo que permitiera el desarrollo de los tejidos de los hongos.

En esta etapa se usó una modificación del medio Melin-Norkrans (MMN), que corresponde a un medio común para el crecimiento de hongos tanto saprófitos, como micorrícicos y parásitos (Marx, 1969). La formulación del medio MMN se muestra en el Cuadro № 1. 
En la etapa de aislación, cada muestra colectada fue registrada en laboratorio en base a una toma fotográfica (Anexo 3) y la asignación del código antes mencionado.

\section{Cuadro $\mathrm{N}^{\circ} 1$ \\ FORMULACIÓN DEL MEDIO MMN MODIFICADO}

\begin{tabular}{|c|c|}
\hline Nutrientes & Cantidad \\
\hline \multicolumn{2}{|c|}{ Fuentes de Carbohidratos } \\
\hline Extracto de Malta & $2 \mathrm{~g}$ \\
\hline D - Glucosa & $5 \mathrm{~g}$ \\
\hline \multicolumn{2}{|c|}{ Nutrientes Minerales } \\
\hline$\left(\mathrm{NH}_{4}\right)_{2} \mathrm{HPO}_{4}$ & $0,25 \mathrm{~g}$ \\
\hline $\mathrm{KH}_{2} \mathrm{PO}_{4}$ & $0,5 \mathrm{~g}$ \\
\hline $\mathrm{MgSO}_{4} \quad 7 \mathrm{H}_{2} \mathrm{O}$ & $0,15 \mathrm{~g}$ \\
\hline $\mathrm{CaCl}_{2}$ & $0,05 \mathrm{~g}$ \\
\hline $\mathrm{FeCl}_{3}$ & $1,2 \mathrm{ml}$ (sol. 1\%) \\
\hline $\mathrm{NaCl}$ & $0,025 \mathrm{~g}$ \\
\hline \multicolumn{2}{|l|}{ Vitaminas } \\
\hline Tiamina $\mathrm{HCl}$ & $100 \mu \mathrm{g}$ \\
\hline Agua Destilada & $1.000 \mathrm{ml}$ \\
\hline $\mathrm{pH}$ & 5,7 \\
\hline Agar & $15 \mathrm{~g}$ \\
\hline
\end{tabular}

Cada hongo fue aislado bajo cámara de flujo laminar, utilizando medios de cultivo previamente confeccionados. Cada aislación se realizó en tres discos Petri para asegurar la aislación de la muestra.

Finalmente, los discos con las aislaciones fueron puestos en una cámara de crecimiento a $23^{\circ} \mathrm{C}$ y en oscuridad, en espera del crecimiento de las cepas y la aislación definitiva.

Para la confección del medio de cultivo se utilizaron frascos Erlhenmeyer de 1 litro, adicionando los productos químicos, vitaminas, carbohidratos y agar correspondientes a la fórmula. Se verificó el $\mathrm{pH}$ mediante un peachímetro, ajustándose este con $\mathrm{KOH} \circ \mathrm{HCl}$, para subir o bajar el $\mathrm{pH}$, respectivamente.

Cada medio fue esterilizado en autoclave a $121^{\circ} \mathrm{C}$ de temperatura, 1,2 atmósferas de presión y un lapso de 20 minutos. Terminada la esterilización de los medios, estos fueron puestos bajo una cámara de flujo laminar, a la espera de su vaciado en discos Petri (Figura $N^{\circ} 1$ ).

El vaciado del medio se realizó con una jeringa estéril con el medio a temperaturas sobre los $50^{\circ} \mathrm{C}$, para evitar su solidificación, agregando $20 \mathrm{ml}$ de medio a cada uno de los discos.

Finalizado el vaciado, se dejaron los discos Petri enfriar, visualizando en ellos el término de la condensación producto de la evaporación (Figura $N^{\circ} 1$ ). Posteriormente, estos fueron guardados o utilizados inmediatamente. 

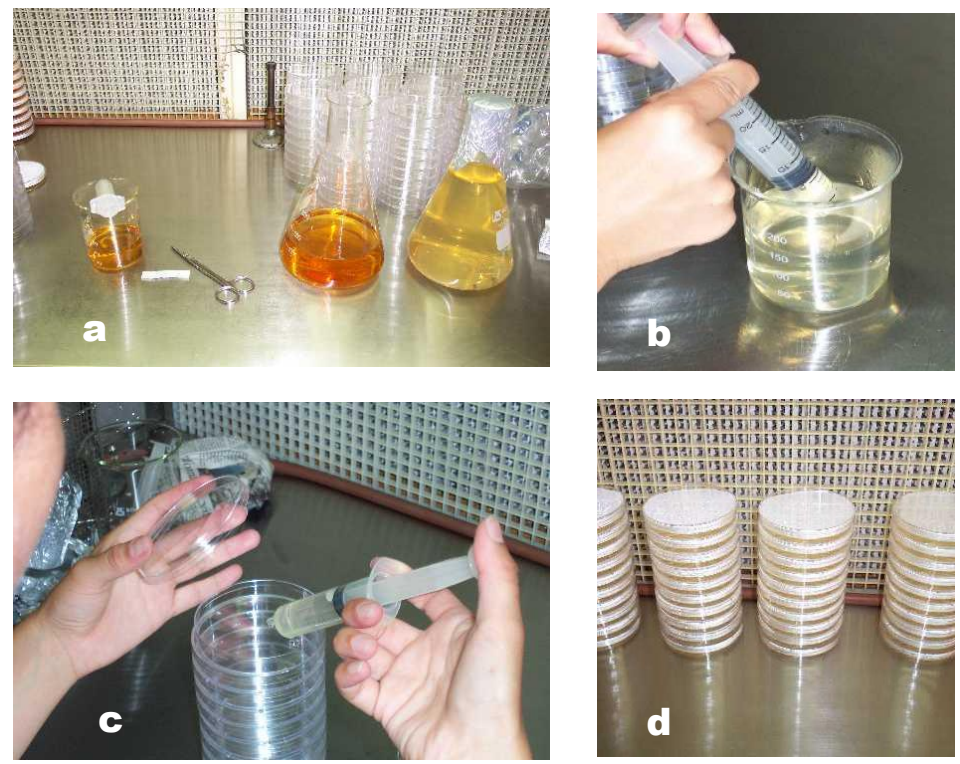
a. Medio de cultivo estéril en cámara de flujo laminar
b. Utilización jeringa estéril para vaciado medio de cultivo a discos Petri
c. Vaciado de medios de cultivo en discos Petri estériles
d. Discos Petri con medios de cultivo en etapa de secado

Figura $\mathrm{N}^{\circ} 1$

AISLACIÓN DE LOS HONGOS

\section{Procedimientos de Aislación de Tejidos}

La inoculación de los medio se realizó bajo una cámara de flujo laminar, tomando un segmento de tejido del cuerpo fructífero del hongo. Para ello, se realizó la segmentación del hongo, dejando expuesto el tejido estéril presente en el interior (Figura $\mathrm{N}^{\circ} 2$ ), permitiendo así la extracción de pequeñas porciones de tejido, los cuales se colocaron sobre el medio de cultivo.

Otro método utilizado fue la colecta de esporas, debido a la dificultad de extraer tejido aséptico o la poca respuesta de este frente al medio de cultivo utilizado para la aislación. Este consistió en colocar un cuerpo fructífero maduro colgando por encima de un medio de cultivo estéril, pero sin tocar el medio, a un par de centímetros por sobre este, para que la caída de las esporas llegue al medio de cultivo. El tiempo de exposición del medio a la caída de las esporas debe ser corto, verificándose constantemente la cantidad de esporas presentes en el medio, para que luego, una vez germinadas las esporas, estas se puedan extraer y aislar sin ningún inconveniente.

Concluidos estos procedimientos, los discos Petri se sellaron con papel parafilm, procediéndose finalmente a marcar con el código de la cepa y la fecha de aislación (Figura $\mathrm{N}^{\circ}$ 2). Posteriormente los discos Petri se colocaron en un ambiente oscuro a $23^{\circ} \mathrm{C}$ de temperatura, para que se desarrolle y se verifique el crecimiento sin presencia de otros contaminantes, como bacterias $\mathrm{u}$ otro hongo contaminante. En el caso de los procedimientos con esporas, estos debieron ser chequeados constantemente, pues esta forma de aislación mostró una alta probabilidad de presentar contaminación por otros hongos y/o bacterias, lo que llevó a un trabajo de aislación más riguroso. Se suma a lo anterior, la rápida germinación de las esporas, no más allá de 3 a 5 días. 

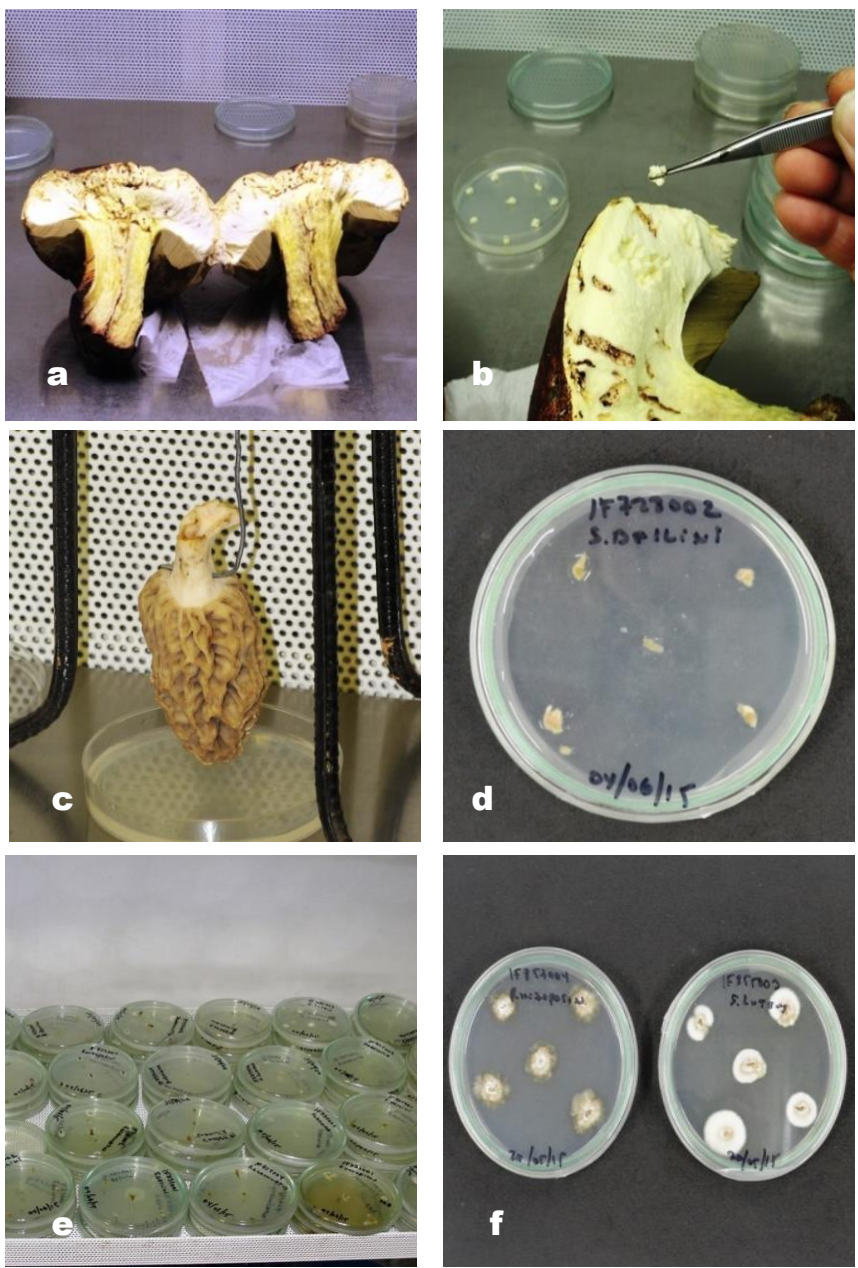
a. Seccionado del cuerpo fructífero para exponer tejido estéril
b. Extracción de tejido estéril para colocarlo en medio de cultivo
c. Colecta de esporas en Morcella
d. Tejido miceliar, sellado con papel parafilm, código y fecha de aislación
e. Discos Petri con tejido aislado puestos en cámara de crecimiento
f. Estado de desarrollo de tejido a los 20 días de su aislamiento

Figura $\mathrm{N}^{\circ} 2$

\section{PROCEDIMIENTOS DE AISLACIÓN DE TEJIDOS}

Para cada cepa aislada se le realizó un seguimiento para ver la evolución del crecimiento y la posible aparición de contaminantes como bacterias y otros hongos. Ante la aparición de agentes contaminantes, se procedió a realizar subcultivos transfiriendo micelio limpio a medio fresco. De esta forma, se logró la aislación definitiva y una cantidad de material suficiente para el montaje de los ensayos de selección de los medios de crecimiento apropiados para cada cepa. 


\section{Determinación de Medios de Crecimiento}

Con las aislaciones definitivas se estableció un ensayo para definir el mejor medio de crecimiento, en términos técnicos y económicos, de entre tres alternativas evaluadas para cada cepa. Los medios utilizados fueron: BAF (Biotina Aneurina Ácido Fólico), MMN (Medio MelinNorkrans) y PDA (Potato Dextrosa Agar), que varían de mayor a menor complejidad y costo (Cuadro $\mathrm{N}^{\circ} 2$ ).

Los ensayos se montaron en discos Petri de vidrio, de $9 \mathrm{~cm}$ de diámetro por $1,5 \mathrm{~cm}$ de altura, previamente esterilizados en autoclave a $1,2 \mathrm{~atm}$, a $120^{\circ} \mathrm{C}$ por $30 \mathrm{~min}$. Los medios se esterilizarán en frascos Erlhenmeyer de $1 \mathrm{~L}$, dispuestos en autoclave a $1,2 \mathrm{~atm}$ de presión y $120^{\circ} \mathrm{C}$ por 20 min. El vaciado del medio a los discos Petri se realizó con jeringa desechable y trabajando en una cámara de flujo laminar previamente esterilizada con alcohol al $70 \%$ y baños de luz ultravioleta. En cada disco Petri fueron depositados $20 \mathrm{ml}$ de medio de cultivo y se dejó enfriar, verificando la eliminación del vapor de agua dentro de cada disco y la solidificación del medio.

Cuadro $\mathrm{N}^{\circ} 2$

FORMULACIÓN DEL MEDIOS DE CRECIMIENTO A EVALUAR

\begin{tabular}{|c|c|c|c|}
\hline \multirow{2}{*}{ Nutrientes } & \multicolumn{3}{|c|}{ Composición de Medios de Cultivo } \\
\hline & Medio MMN & Medio BAF & Medio PDA \\
\hline \multicolumn{4}{|l|}{ Fuentes de Carbohidratos } \\
\hline Extracto de levadura & & $0,2 \mathrm{~g}$ & \\
\hline Extracto de papa & & & $4 \mathrm{~g}$ \\
\hline Extracto de Malta & $2 \mathrm{~g}$ & & \\
\hline Peptona & & $2 \mathrm{~g}$ & \\
\hline D - Glucosa & $10 \mathrm{~g}$ & $30 \mathrm{~g}$ & $20 \mathrm{~g}$ \\
\hline \multicolumn{4}{|l|}{ Nutrientes Minerales } \\
\hline$\left(\mathrm{NH}_{4}\right)_{2} \mathrm{HPO}_{4}$ & $0,25 \mathrm{~g}$ & & \\
\hline $\mathrm{FeCl}_{3} \cdot 6 \mathrm{H}_{2} \mathrm{O}$ & & $10 \mathrm{mg}$ & \\
\hline $\mathrm{ZnSO}_{4} \cdot 7 \mathrm{H}_{2} \mathrm{O}$ & & $1 \mathrm{mg}$ & \\
\hline $\mathrm{MnSO}_{4} \cdot 4 \mathrm{H}_{2} \mathrm{O}$ & & $5 \mathrm{mg}$ & \\
\hline $\mathrm{KH}_{2} \mathrm{PO}_{4}$ & $0,5 \mathrm{~g}$ & $0,5 \mathrm{~g}$ & \\
\hline $\mathrm{MgSO}_{4} \cdot 7 \mathrm{H}_{2} \mathrm{O}$ & $0,15 \mathrm{~g}$ & $0,5 \mathrm{~g}$ & \\
\hline $\mathrm{CaCl}_{2}$ & $0,05 \mathrm{~g}$ & $100 \mathrm{mg}$ & \\
\hline $\mathrm{FeCl}_{3}$ & $1,2 \mathrm{ml}$ (sol. 1\%) & & \\
\hline $\mathrm{NaCl}$ & $0,025 \mathrm{~g}$ & & \\
\hline \multicolumn{4}{|l|}{ Vitaminas } \\
\hline Tiamina $\mathrm{HCl}$ & $0,01 \mathrm{mg}$ & $0,05 \mathrm{mg}$ & \\
\hline Biotina & & $0,001 \mathrm{mg}$ & \\
\hline Ácido Fólico & & $0,1 \mathrm{mg}$ & \\
\hline Inositol & & $50 \mathrm{mg}$ & \\
\hline Agua Destilada & $1.000 \mathrm{ml}$ & $1.000 \mathrm{ml}$ & $1.000 \mathrm{ml}$ \\
\hline $\mathrm{pH}$ & 5,6 & 5,6 & 5,6 \\
\hline Agar & $15 \mathrm{~g}$ & $15 \mathrm{~g}$ & $15 \mathrm{~g}$ \\
\hline
\end{tabular}

Para la inoculación de cada cepa en los discos con medios de cultivo, se utilizaron dos sacabocados que permitían obtener círculos de micelio de 1,4 y de 0,7 cm de diámetro a partir del crecimiento inicial en los trabajos de aislación.

La instalación de los ensayos se realizó bajo un ambiente estéril dado por una cámara de flujo laminar, dentro de la cual se realizó la inoculación de los medios de cultivo. Esta se instaló, utilizando los círculos de micelio obtenidos y extraídos con un asa estéril para su ubicación en los 
medios de cultivo. Una vez realizadas las inoculaciones, los discos sellados y codificados se colocaron en la cámara de crecimiento bajo oscuridad y a $23^{\circ} \mathrm{C}$ de temperatura. En el ensayo fueron evaluados tres medios de cultivo para cada cepa aislada, donde cada medio fue representado por tres repeticiones de un disco Petri cada una, totalizando 9 discos por cepa.

La evaluación del crecimiento de las cepas en los medios de cultivo se realizó después de 30 días de incubar los discos Petri en oscuridad a $23^{\circ} \mathrm{C}$. La evaluación del crecimiento consistió en medir con una regla el crecimiento radial de la cepa en cuatro direcciones, tomando como punto 0 , el centro del disco de micelio usado para inocular el medio de cultivo. Una vez realizada cada medición, a cada una de ellas se le restó el radio del círculo puesto inicialmente, para obtener finalmente el crecimiento real.

Los datos obtenidos fueron digitados y depurados, para posteriormente realizar los análisis de varianza y comparación múltiple de medias (test de Tuckey con alfa $=0,05$ ) utilizando el software estadístico INFOSTAT, con el propósito de identificar el medio que permitiera el mayor crecimiento de cada cepa.

Para realizar las mediciones de crecimiento radial para cada una de las cepas de hongos comestibles, se confeccionó un formulario para registro de las mediciones realizadas (Anexo 4).

\section{RESULTADOS}

\section{Prospección y Colecta de Hongos}

Los datos de los formularios de prospección y colecta en terreno, se muestran en las tablas del Anexo 2. Como resultado final de la campaña de terreno (Figura $N^{\circ} 3$ ), se contabilizó un total de 95 cepas colectadas para las dos regiones contempladas.

Para la región de Maule, se obtuvo un total de 27 cepas, 21 de las cuales corresponden a cepas de especies comestibles. En tanto que para la región de Bio Bio, se recolectó un total de 68 cepas, 44 de ellas de tipo comestible. En total fueron recolectadas 95 cepas de las cuales 65 fueron cepas de hongos comestibles (Anexos 2 y 3 ).
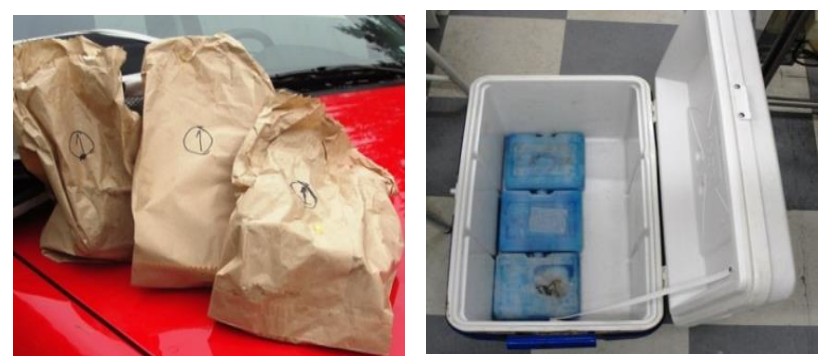

Figura $N^{\circ} 3$

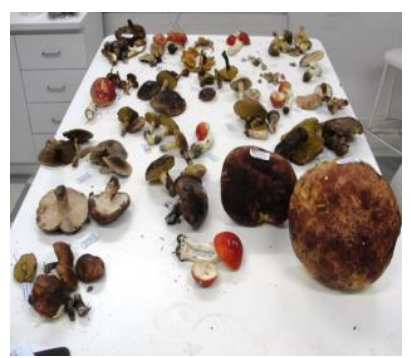

MUESTRAS EN BOLSA DE PAPEL CON CÓDIGO QUE IDENTIFICA EL SITIO (IZQ), MUESTRAS EN CONTENEDOR CON ICEPACK PARA MANTENER A $3-4^{\circ} \mathrm{C}$ (CENTRO) Y ORDENACIÓN Y CODIFICACIÓN DE MATERIAL EN LABORATORIO (DER)

\section{Aislación de Cepas}

La respuesta de las cepas a la metodología de aislación utilizada fue variable, observándose crecimientos muy lentos como fue el caso de Boletus loyo, que en una de las cepas no alcanzó a originar suficiente tejido para su evaluación en otros medios de cultivo.

Otros en cambio, no respondieron al medio, como en el caso de Cortinarius lebre, cuyos 
tejidos aislados permanecieron inertes, sin presentar contaminación alguna.

Se observó también contaminación de algunos tejidos aislados dentro de los cultivos (Figura $\mathrm{N}^{\circ} 4$ ), lo que generó un inmediato proceso de subcultivo para la eliminación de la contaminación respectiva, lográndose una eliminación exitosa en la mayoría de los tejidos de las cepas aisladas, después de unos meses de trabajo.

En otros casos las cepas no pudieron ser separadas del organismo contaminante, por lo que estos aislados se perdieron

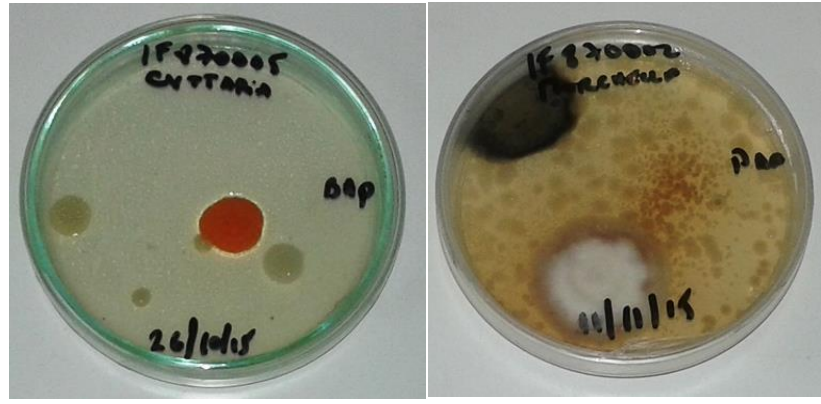

Figura $\mathrm{N}^{\circ} 4$

CONTAMINACIÓN DE CEPAS POR BACTERIAS (IZQ) Y POR HONGOS (DER)

Como resultado de las aislaciones iniciales y limpieza de contaminaciones, el número de cepas definitivamente aisladas, fue de 24 para región de Maule, de las cuales 21 pertenecen a hongos comestibles, y 63 para la Región de Bio Bio, de las cuales 41 corresponden a cepas de hongos comestibles.

Como resultado final, se obtuvieron 87 cepas aisladas, de las cuales 62 corresponden a hongos comestibles y sobre las cuales se evaluaron los diferentes medios.

\section{Selección de Medios de Cultivo}

Una vez realizada la instalación de los ensayos y las respectivas mediciones se realizó el análisis de los datos (Figura $\mathrm{N}^{\circ} 5$ ).

Los resultados de los crecimientos promedios de las cepas para cada medio y cepa, junto con los resultados de los análisis estadísticos, se muestran en los Cuadros $\mathrm{N}^{\circ} 3$ y $\mathrm{N}^{\circ} 4$ donde se presentan los valores promedios de crecimiento para cada una de las cepas de hongos comestibles, en cada uno de los medios evaluados. 

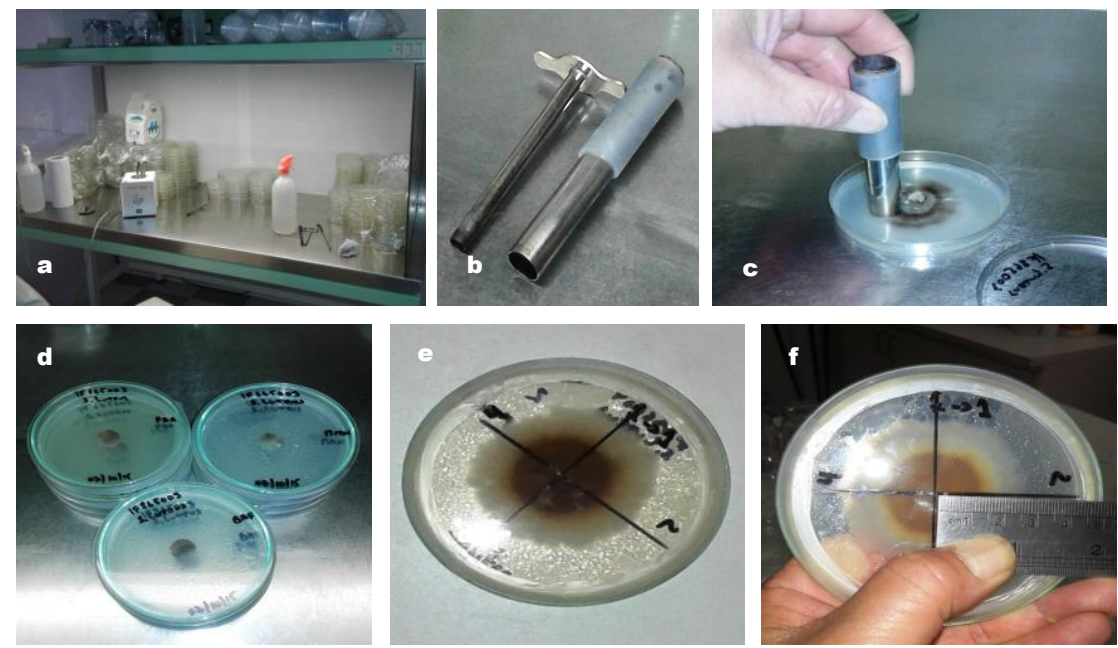

a. Instalación de ensayos bajo ambiente estéril en cámara de flujo laminar

b. Sacabocados de acero y elaboración de discos de micelio

c. Elaboración de discos de inoculación

d. Aspecto de los discos de micelio puesto en los medios

e. Marcaje de líneas

f. Medición de crecimiento radial

\section{Figura $\mathbf{N}^{\circ} 5$ \\ INSTALACIÓN DE LOS ENSAYOS DE MEDIOS Y MEDICIÓN}

A nivel de especies, el análisis de los datos permite indicar que:

Rhizopogon roseolus exhibe diferentes respuestas en sus distintas cepas; las cepas IF857004, IF829001 y IF732001 presentan crecimientos significativamente superiores en el medio MMN en comparación a los medios BAF y PDA. Mientras que para las cepas de IF736001 y IF734003, muestra crecimientos mayores en el medio BAF, siendo significativamente superiores a MMN y PDA.

- Boletus loyo muestra un crecimiento muy lento en sus distintas cepas, verificándose un crecimiento de apenas 0,1 a $0,2 \mathrm{~cm}$ a los 30 días. Se observa, además, que existen comportamientos distintos de las tres cepas evaluadas. Para el caso de la cepa IF737001, presenta un crecimiento en el medio BAF significativamente diferente frente a los otros medios, PDA y MMN, en los que no se presentó crecimiento. Respecto a la cepa IF84001, hubo crecimiento tanto para el medio BAF como para MMN, pero no para el medio PDA, en el que no presentaba crecimiento, y con diferencias significativas frente al medio BAF. Finalmente, para la cepa IF83001 se presenta solo crecimiento en medio MMN, presentando diferencias significativas con el resto de los medios.

- Las dos cepas del saprófito Agrocybe aegerita presentan un crecimiento bastante rápido, colonizando los 3 medios de cultivo por igual e invadiendo en su totalidad la superficie de estos sin diferencias de crecimiento para los tres medios evaluados.

- Para las especies y cepas de Morchella se evidencia un crecimiento bastante rápido en el medio de cultivo BAF, completando a los 30 días toda su superficie, en todos los casos con diferencias significativas respecto a los otros dos medios, MMN y PDA. 
Cuadro $\mathrm{N}^{\circ} 3$

SELECCIÓN DE MEDIOS DE CULTIVO PARA CEPAS DE HONGOS COMESTIBLES

PARA LA REGIÓN DEL BIO BIO

\begin{tabular}{|c|c|c|c|c|c|c|c|c|c|}
\hline \multirow[t]{2}{*}{ Región } & \multirow{2}{*}{$\begin{array}{c}\text { Código } \\
\text { Cepa }\end{array}$} & \multirow[t]{2}{*}{ Especie } & \multirow{2}{*}{$\begin{array}{c}\mathrm{N}^{\circ} \\
\text { Repet. }\end{array}$} & \multicolumn{6}{|c|}{$\begin{array}{c}\text { Crecimento radial en Medios } \\
\text { de Cultivo (cm) }\end{array}$} \\
\hline & & & & PDA & $*$ & $\mathrm{MMN}$ & $*$ & BAF & $*$ \\
\hline Bio Bio & IF854001 & Suillus luteus & 3 & 1,83 & $\mathrm{~b}$ & 1,09 & $a$ & 1,84 & $\mathrm{~b}$ \\
\hline Bio Bio & IF855003 & Suillus luteus & 3 & 1,45 & a & 1,38 & $a$ & 2,04 & $b$ \\
\hline Bio Bio & IF856002 & Suillus luteus & 3 & 0,85 & a & 1,06 & $a b$ & 1,23 & $b$ \\
\hline Bio Bio & IF857001 & Suillus bellini & 3 & 0,45 & a & 1,26 & $c$ & 0,90 & $b$ \\
\hline Bio Bio & IF857003 & Bovista $s p$ & 3 & 0,98 & $b$ & 0,29 & a & 1,13 & $b$ \\
\hline Bio Bio & IF857004 & Rhizopogon luteolus & 3 & 1,58 & a & 1,89 & $b$ & 1,59 & a \\
\hline Bio Bio & IF858004 & Suillus luteus & 3 & 1,23 & a & 1,18 & a & 1,63 & $b$ \\
\hline Bio Bio & IF859002 & Suillus bellini & 3 & 0,85 & a & 0,98 & a & 0,91 & a \\
\hline Bio Bio & IF860001 & Suillus luteus & 3 & 1,16 & a & 1,23 & $a$ & 1,42 & a \\
\hline Bio Bio & IF861001 & Suillus luteus & 3 & 1,26 & $b$ & 0,57 & $a$ & 1,59 & $b$ \\
\hline Bio Bio & IF862002 & Suillus granulatus & 3 & 1,31 & a & 1,56 & $a$ & 1,69 & a \\
\hline Bio Bio & IF862003 & Agrocybe aegerita & 3 & 3,50 & a & 3,50 & a & 3,50 & a \\
\hline Bio Bio & IF862004 & Lactarius deliciosus & 3 & 0,18 & a & 0,81 & $b$ & 0,72 & $b$ \\
\hline Bio Bio & IF862005 & Ramaria flava & 3 & 1,58 & a & 2,10 & $\mathrm{~b}$ & 3,29 & c \\
\hline Bio Bio & IF862007 & Ramaria botrytis & 3 & 2,93 & a & 2,68 & $a$ & 2,73 & a \\
\hline Bio Bio & IF862008 & Suillus luteus & 3 & 1,19 & a & 1,29 & $a$ & 1,80 & $b$ \\
\hline Bio Bio & IF863001 & Boletus loyo & 3 & 0,00 & a & 0,08 & $b$ & 0,00 & a \\
\hline Bio Bio & IF864001 & Boletus loyo & 3 & 0,00 & a & 0,10 & $a b$ & 0,19 & $b$ \\
\hline Bio Bio & IF865003 & Suillus luteus & 3 & 1,19 & a & 1,45 & $\mathrm{~b}$ & 1,65 & $b$ \\
\hline Bio Bio & IF866002 & Suillus luteus & 3 & 1,33 & a & 1,53 & $a$ & 1,48 & a \\
\hline Bio Bio & IF867001 & Suillus granulatus & 3 & 1,28 & a & 1,64 & $a b$ & 1,88 & b \\
\hline Bio Bio & IF867002 & Suillus luteus & 3 & 1,56 & a & 1,24 & $a$ & 1,63 & $a$ \\
\hline Bio Bio & |F868001 & Suillus luteus & 3 & 1,17 & a & 1,61 & a & 1,43 & a \\
\hline Bio Bio & IF868003 & Suillus bellini & 3 & 0,83 & a & 0,93 & a & 0,90 & a \\
\hline Bio Bio & IF869001 & Agrocybe aegerita & 3 & 3,50 & a & 3,50 & a & 3,50 & $a$ \\
\hline Bio Bio & IF870001 & Morchella esculenta & 3 & 0,64 & a & 0,48 & a & 2,87 & $b$ \\
\hline Bio Bio & IF870002 & Morchella elata & 3 & 1,56 & $b$ & 0,63 & a & 3,85 & $\mathrm{c}$ \\
\hline Bio Bio & IF870003 & Morchella conica & 3 & 2,68 & $b$ & 0,15 & a & 3,85 & $\mathrm{c}$ \\
\hline Bio Bio & IF870005 & Cyttaria berteroi & 3 & 0,30 & a & 0,34 & $a$ & 3,36 & $b$ \\
\hline Bio Bio & IF871001 & Rhizopogon luteolus & 3 & 0,37 & a & 1,23 & $b$ & 1,27 & $b$ \\
\hline Bio Bio & IF871002 & Suillus luteus & 3 & 1,14 & a & 1,23 & $a b$ & 1,36 & $b$ \\
\hline Bio Bio & IF872001 & Suillus granulatus & 3 & 1,01 & a & 1,23 & $b$ & 1,59 & c \\
\hline Bio Bio & IF873001 & Morchellasp & 3 & 1,78 & $b$ & 0,33 & $a$ & 3,85 & $\mathrm{c}$ \\
\hline Bio Bio & IF873003 & Suillus luteus & 3 & 1,02 & a & 1,08 & a & 1,27 & $b$ \\
\hline Bio Bio & IF874001 & Suillus luteus & 3 & 0,94 & $b$ & 0,05 & a & 1,08 & $b$ \\
\hline Bio Bio & IF874002 & Rhizopogon luteolus & 3 & 0,96 & a & 1,28 & $b$ & 1,28 & $b$ \\
\hline Bio Bio & IF875001 & Coprinus comatus & 3 & 3,07 & a & 3,85 & $b$ & 3,85 & b \\
\hline Bio Bio & IF875002 & Morchella sp & 3 & 2,37 & $b$ & 0,73 & a & 3,85 & $\mathrm{c}$ \\
\hline Bio Bio & IF876001 & Morchella sp & 3 & 1,12 & a & 1,08 & a & 3,85 & b \\
\hline Bio Bio & IF877001 & Coprinus comatus & 3 & 2,18 & a & 2,32 & a & 3,85 & $b$ \\
\hline
\end{tabular}

Nota: * Test:Tukey Alfa $=0,05$

Medias con una letra común en la misma fila no son significativamente diferentes $(p>0,05)$ 
Cuadro $\mathrm{N}^{\circ} 4$

SELECCIÓN DE MEDIOS DE CULTIVO PARA CEPAS DE HONGOS COMESTIBLES

PARA LA REGIÓN DEL MAULE

\begin{tabular}{|c|c|c|c|c|c|c|c|c|c|}
\hline \multirow[t]{2}{*}{ Región } & \multirow[t]{2}{*}{$\mathrm{N}^{\circ} \mathrm{Cepa}$} & \multirow[t]{2}{*}{ Especie } & \multirow{2}{*}{$\begin{array}{c}\mathrm{N}^{\circ} \\
\text { Repet. }\end{array}$} & \multicolumn{6}{|c|}{$\begin{array}{c}\text { Crecimento radial en Medios } \\
\text { de Cultivo }(\mathrm{cm})\end{array}$} \\
\hline & & & & PDA & * & MMN & * & BAF & * \\
\hline Maule & IF728002 & Suillus bellini & 3 & 0,46 & $\mathrm{a}$ & 1,24 & $\mathrm{~b}$ & 1,26 & $\mathrm{~b}$ \\
\hline Maule & IF728001 & Suillus granulatus & 3 & 1,28 & $\mathrm{~b}$ & 1,28 & $b$ & 0,78 & a \\
\hline Maule & IF729001 & Rhizopogon luteolus & 3 & 0,32 & a & 1,78 & c & 1,36 & $b$ \\
\hline Maule & IF730001 & Suillus bellini & 3 & 0,82 & a & 1,23 & $b$ & 1,39 & $\mathrm{~b}$ \\
\hline Maule & IF731001 & Suillus bellini & 3 & 0,69 & a & 1,51 & $b$ & 1,46 & $b$ \\
\hline Maule & IF731002 & Suillus granulatus & 3 & 0,68 & a & 1,95 & c & 1,46 & $b$ \\
\hline Maule & IF732001 & Rhizopogon luteolus & 3 & 1,29 & a & 2,14 & $b$ & 1,65 & a \\
\hline Maule & IF732002 & Suillus granulatus & 3 & 1,28 & a & 1,52 & a & 2,24 & b \\
\hline Maule & IF732003 & Suillus luteus & 3 & 0,68 & a & 1,52 & $b$ & 2,32 & c \\
\hline Maule & IF732004 & Suillus bellini & 3 & 0,93 & $a$ & 0,94 & a & 1,38 & $b$ \\
\hline Maule & IF733002 & Suillus bellini & 3 & 0,68 & $a$ & 1,13 & $b$ & 1,09 & b \\
\hline Maule & IF734002 & Suillus luteus & 3 & 1,13 & a & 1,25 & a & 1,74 & b \\
\hline Maule & IF734003 & Rhizopogon luteolus & 3 & 0,80 & a & 1,77 & $b$ & 2,18 & c \\
\hline Maule & IF734004 & Rhizopogon sp. & 3 & 0,99 & $a$ & 1,83 & $b$ & 1,77 & $b$ \\
\hline Maule & IF735001 & Suillus bellini & 3 & 0,81 & a & 1,52 & c & 1,14 & b \\
\hline Maule & IF735003 & Suillus luteus & 3 & 1,11 & a & 1,18 & a & 1,73 & b \\
\hline Maule & IF735004 & Suillus granulatus & 3 & 0,91 & a & 1,45 & $b$ & 1,69 & b \\
\hline Maule & IF736001 & Rhizopogon luteolus & 3 & 0,87 & a & 1,73 & b & 2,40 & c \\
\hline Maule & IF736004 & Suillus luteus & 3 & 1,30 & a & 1,44 & a & 1,81 & b \\
\hline Maule & IF736005 & Agaricus campestris & 3 & 1,62 & c & 0,13 & a & 0,50 & b \\
\hline Maule & IF737001 & Boletus loyo & 3 & 0,00 & a & 0,00 & a & 0,10 & $b$ \\
\hline
\end{tabular}

Nota: * Test:Tukey Alfa $=0,05$

Medias con una letra común en la misma fila no son significativamente diferentes $(p>0,05)$

- $\quad$ Las cepas de Suillus luteus muestran distintas preferencias por los medios de cultivo; algunas no exhiben diferencias significativas entre los medios, mientras que otras presentan mayor crecimiento en los medios MMN y BAF sin presentar diferencias significativas entre ellas. Por otra parte, un gran porcentaje de las cepas presenta buen crecimiento en el medio BAF y diferencias significativas respecto a los otros dos medios.

Suillus bellini y Suillus granulatus presentan un comportamiento similar a Suillus luteus, en lo que respecta al comportamiento de sus diferentes cepas frentes a los distintos medios de cultivo. En ellos se presentan crecimientos diferentes para cada cepa. Algunos presentan mayores crecimientos en el medio MMN, otros en medio BAF, otros poseen un crecimiento similar para las tres cepas, mientras que otros presentan mayores crecimientos en los medios MMN y BAF.

Cyttaria berteroi, presenta un comportamiento similar a las especies de Morchella, con un comportamiento lento para los medios PDA y MMN, pero un crecimiento bastante rápido en el medio BAF, presentando diferencias significativas con respecto a los otros medios.

- Las dos cepas de Coprinus comatus presentan buen crecimiento en el medio BAF, aunque la cepa IF875001 no exhibe diferencias significativas con respecto al crecimiento observado en el medio MMN. 
- Ramaria botrytis presenta mayor crecimiento en el medio PDA, aunque sin diferencias significativas respecto a los otros medios. En cambio, para Ramaria flava el mayor crecimiento se presenta en el medio más completo, el medio BAF, con diferencias significativas respecto a los medios restantes.

- Agaricus campestris y Bovista sp., de comportamiento saprófito, presentan buenos crecimientos en el medio PDA, con una media con diferencias significativas respecto a los medios MMN y BAF para el caso de A. campestris, en tanto que para Bovista sp., esta diferencia solo se da para el medio MMN.

- Lactarius deliciosus presenta buenos crecimientos tanto para el medio BAF como para el MMN, con medias significativamente diferentes frente al medio PDA.

\section{CONCLUSIONES}

Las tareas de colecta de material fúngico se vieron afectadas por la prolongada sequía que se apreció en las dos regiones a prospectar. Esto produjo un retraso en las labores contempladas, retrasando la temporada de producción de hongos y la aparición de hongos comestibles, como es el caso de especies como Lactarius deliciosus, Suillus luteus y Suillus granulatus en los bosques de pino y de Boletus loyo, Cortanarius lebre, Ramaria flava o R. botrytis, entre otras, para los bosques con especies nativas.

A pesar de lo estrecho del período de colecta en la primera temporada de colecta (otoño), se hizo una buena parte del trabajo contemplado, logrando la aislación de especies como Suillus luteus, S. granulatus, S. Bellini, Lactarius deliciosus y Rhizopogon luteolus, además de Boletus loyo en Bosque nativo.

La normalización de las lluvias en el período de primavera y el alargue de estas hasta el mes de noviembre, favoreció la presencia de otros hongos como las especies de los géneros Bovista, Coprinus, Cyttaria y Morchella, colectándose incluso algunos especímenes de Suillus.

En total se realizaron 97 colectas de cepas, de las cuales 65 correspondieron a cepas de hongos comestibles, 21 para la Región del Maule y 44 para la Región del Bio Bio. De estas se lograron aislar un total de 87 cepas, de las cuales 62 corresponden a cepas de hongos comestibles, 21 para la Región del Maule y 41 para la Región del Bio Bio, lográndose el cumplimiento del objetivo al incorporar un banco de hongos comestibles en el Cepario de INFOR, con la mayoría de las especies presentes en las dos regiones.

Sin embargo, se deberá ir actualizando y completando el cepario con especies de difícil aislación, como Cortinarius lebre. También se deberá seguir colectando cepas, con el propósito de aumentar la variabilidad genética regional de cada especie fúngica comestible resguardada en el cepario.

Los trabajos realizados para la aislación de las cepas, permitieron aislar cerca del $90 \%$ de las cepas colectas con aproximadamente un $10 \%$ de pérdidas por contaminación bacteriana o fúngica, nula respuesta al medio de cultivo o nula esporada de los cuerpos fructíferos al momento de la cosecha de estas.

Respecto a los ensayos para evaluar 3 tipos de medios de cultivo y establecer el medio más favorable para el crecimiento de cada cepa, se pudo constatar que algunos hongos no presentaban preferencias por alguno de ellos, como la especie Agrocybe aegerita, mientras que en otros se observó un mayor crecimiento en uno o dos de los tres medios evaluados.

De las medias obtenidas se puede ver que no existe un medio común que pueda ser el más eficaz para obtener el mayor crecimiento para un especie fúngica en particular, 
demostrándose que existen comportamientos diferentes entre cepas de una misma especie.

Para el caso de Boletus loyo su crecimiento en los diferentes medios podría indicar un lento crecimiento miceliar o medios utilizados no aptos para el crecimiento de esta especie, lo cual lleva a seguir investigando para definir medios de crecimiento que sean óptimos para esta especie.

El conocimiento acabado del comportamiento de los hongos y las diferentes cepas de estos en medios específicos requerirá de mayores estudios para definir medios específicos para cepas específicas, buscando precisar no solo el medio preciso para su crecimiento, sino que además sus requerimientos ambientales.

\section{REFERENCIAS}

Catalán, R., 2006. La Otra Oferta de los Árboles Nativos: No sólo madera da el bosque. Coordinador del Programa de Conservación con Comunidades de la oficina en Chile del Fondo Mundial para la Vida Silvestre (WWF). [En línea] <http://www.lignum.cl/noticias/imprimir_noticia.php?id=8046> (Consulta :13 de diciembre 2006).

CONAF, 1997. Catastro y Evaluación de los Recursos Vegetacionales Nativos de Chile. Corporación Nacional Forestal (CONAF).

INFOR, 2004. Innovación Tecnológica y Comercial de Productos Forestales No Madereros (PFNM) en Chile. [En línea] < http://www.gestionforestal.cl/pfnm/index. htm>. (Consulta :13 de abril 2008).

Marx, D. H., 1969. The Influence of Ectotrophic Mycorrhizal Fungi on the Resistance of Pine Roots to Pathogenic Infections. I. Antagonism of Mycorrhizal Fungi to Root Patogenic Fungi and soil Bacteria. Phytopathology, 59, 153163. 1969.

Peters, C. 1996. The Ecology and Management of Non Timber Forest Resources. World Bank Technical. Paper 322. Washington, D.C., USA. 157 p.

Real, P. 1990. Zonas de Crecimiento de Pino Radiata. 27 p.

Saavedra, J., 2004. Análisis del Proceso de Comercialización de Semillas Forestales y Ornamentales en Dos Centros de Semillas. Memoria para optar al título de Ingeniería Forestal. Universidad De Chile, Facultad de Ciencias Forestales, Escuela de Ciencias Forestales, Departamento de Manejo de Recursos Forestales. 104 p.

Tacón, A. y Palma, J., 2005. Productos Forestales No Madereros. En: Bosques y comunidades del sur de Chile. Editado por Catalán, R; Wilken, P; Kandzior, A.; Tecklin, A. y H. Burschel. Editorial Universitaria, Chile. Pp: 253266.

Taller de Acción Cultural (TAC), 2003. Recolectoras de Frutos Silvestres. Oficio de Mujeres en la Región del Bio Bio. Santiago de Chile. Serie de Derechos Laborales. 135 p. 
ANEXO 1

Mapas Vegetacionales para Bosques de Nothofagus y Plantaciones de Pinus radiata

Mapas Vegetacionales para Bosques de Nothofagus

Mapa de la Región de Maule con Presencia de Masas Vegetacionales con Participación de Roble, Raulí, Coihue, Hualo y Ruil

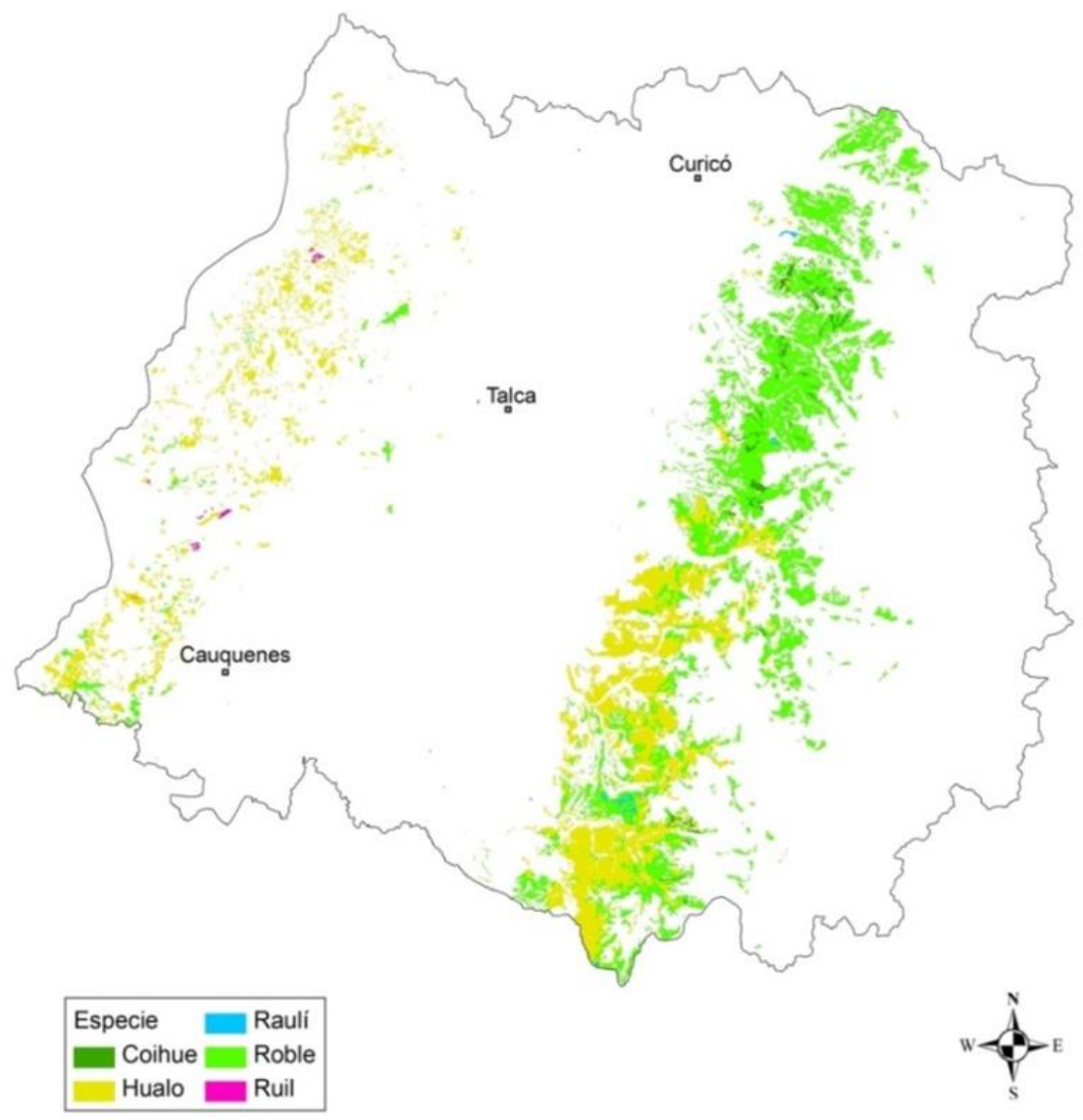




\section{Mapa de la Región de Bio Bio con Presencia de Masas Vegetacionales}

con Participación de Roble, Raulí, Coihue y Hualo

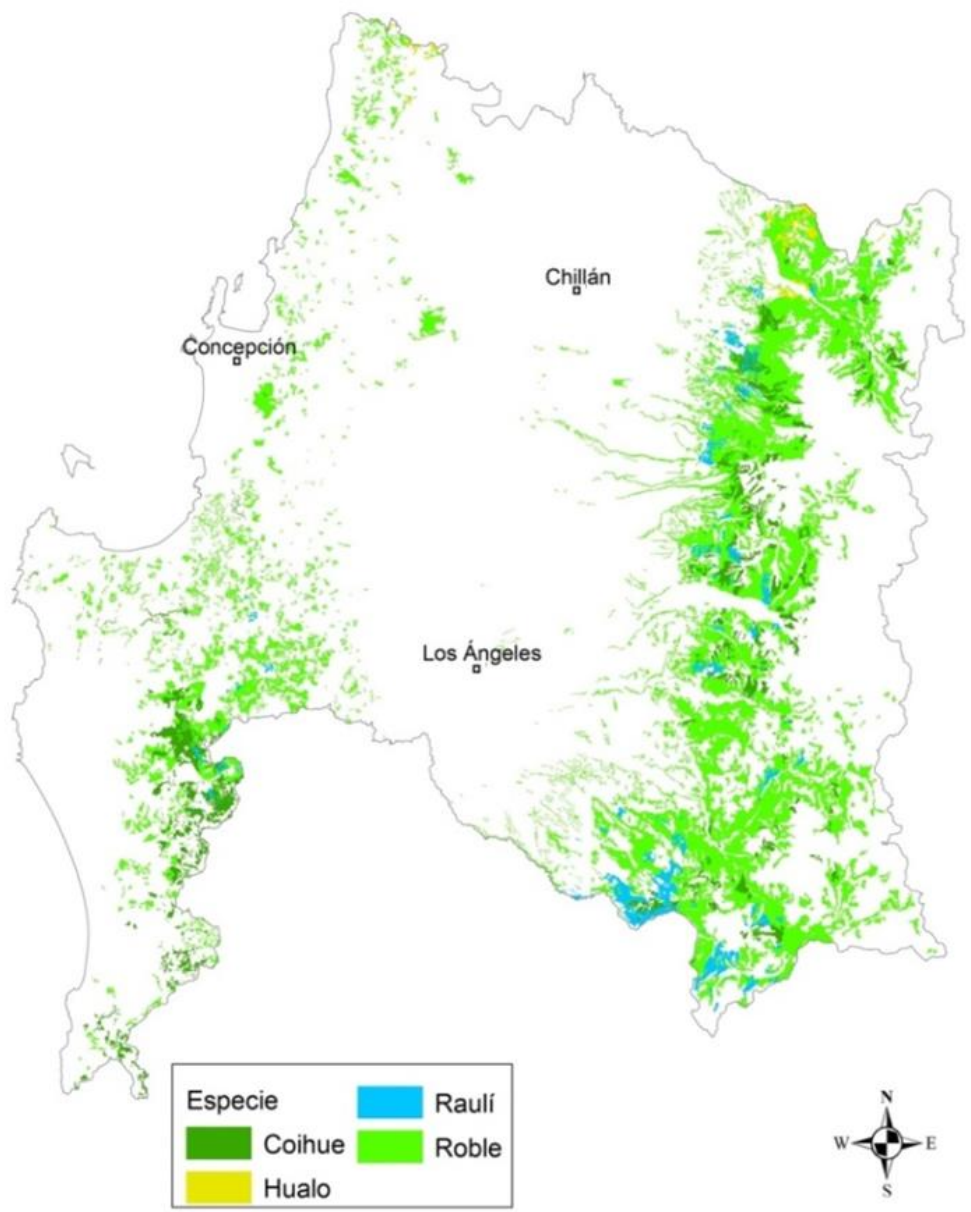


Mapas Vegetacionales para Plantaciones de Pinus radiata

Mapa con Zonas de Crecimiento de Pinus radiata para la Región de Maule

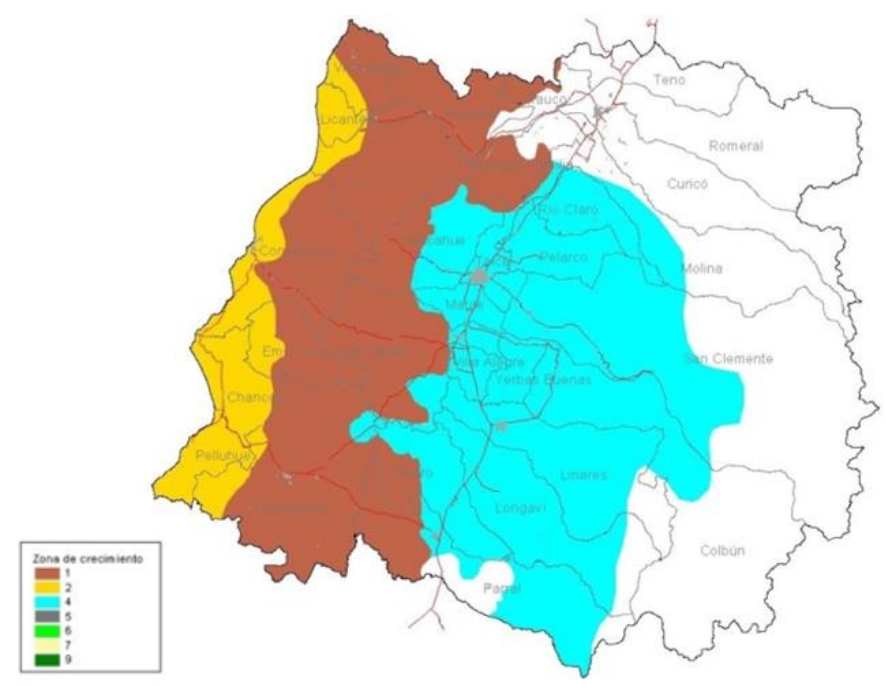




\section{Mapa con Zonas de crecimiento de Pinus radiata}

para la Región de Bio Bio

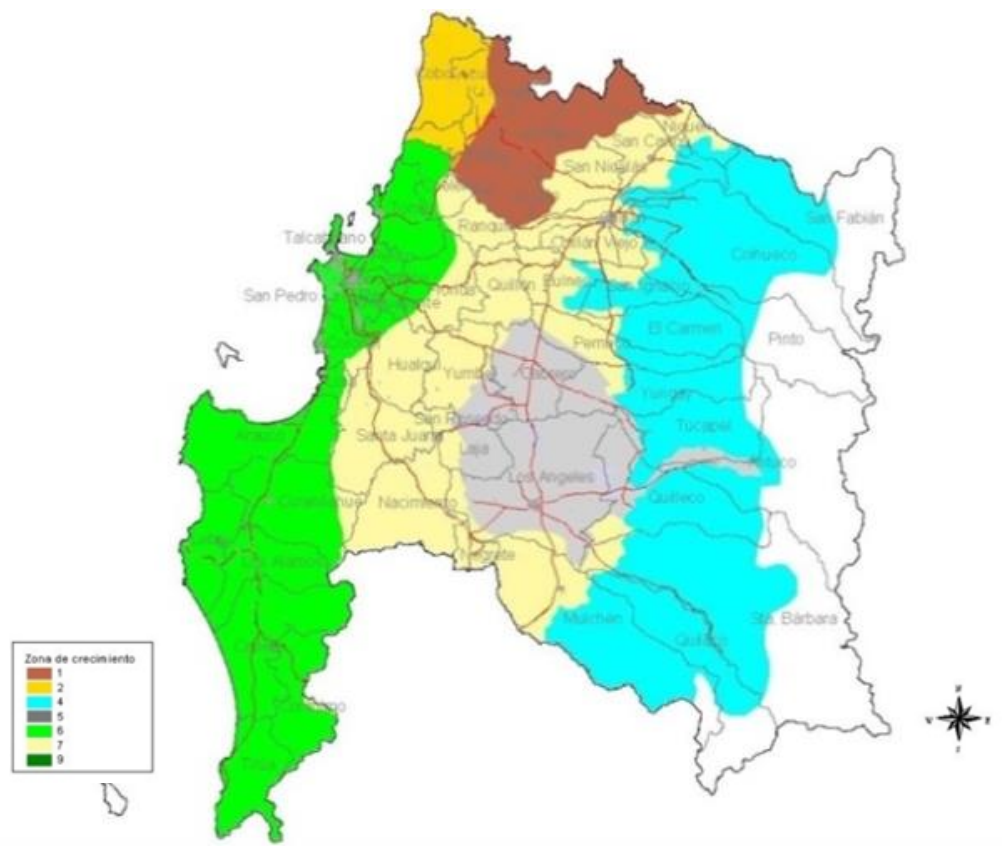




\section{ANEXO 2 \\ Tabla de Cepas Recolectadas con Códigos Asignados e Información de Sitios de Colecta por Región}

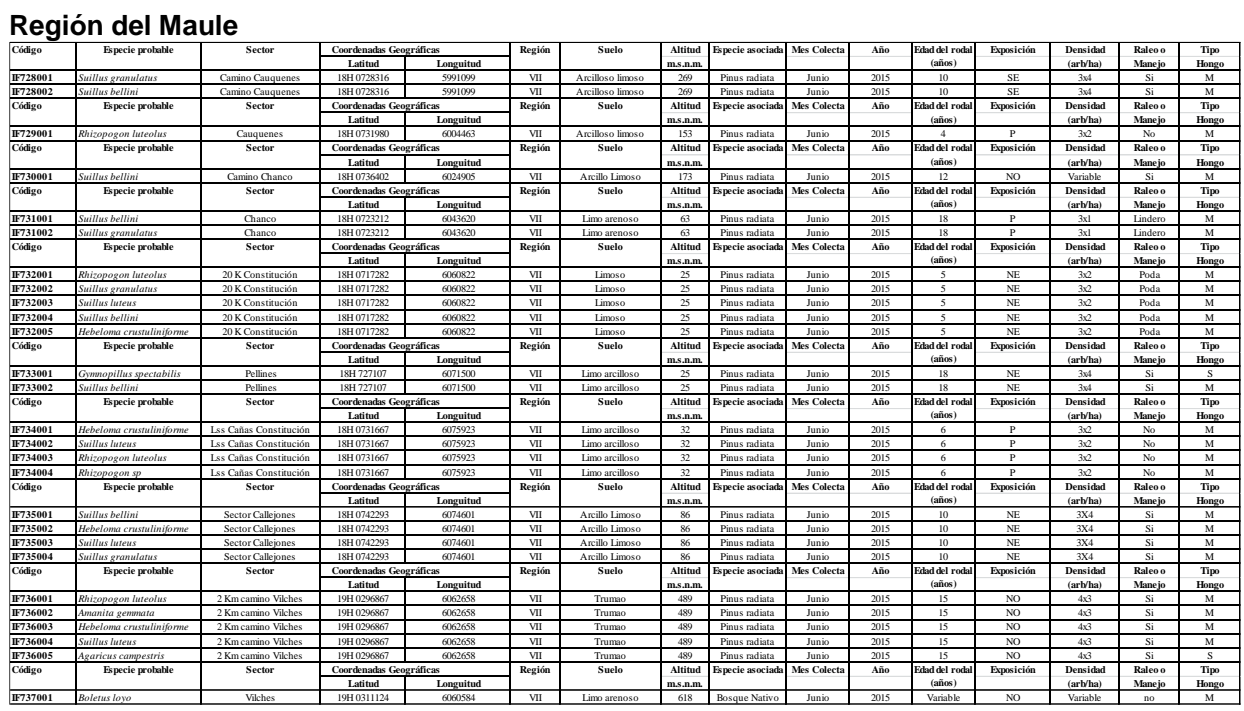

\section{Región del Bio Bio}

\begin{tabular}{|c|c|c|c|c|c|c|c|c|c|c|c|c|c|c|c|}
\hline Coxligo & Especie probabale & Sector & \begin{tabular}{|c} 
Coordenadas Gee \\
Latitud
\end{tabular} & graficicas & Regaín & Suelo & \begin{tabular}{|c|} 
Altitud \\
ms.nmm
\end{tabular} & Especie asociada & Mes Colecta & Año & 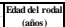 & Exposición & $\begin{array}{l}\text { Densidad } \\
\text { (arbhlaal }\end{array}$ & $\begin{array}{l}\text { Raleo o } \\
\text { Manejo }\end{array}$ & $\begin{array}{c}\text { Tipo } \\
\text { Hongo }\end{array}$ \\
\hline \begin{tabular}{|l|} 
IF864001 \\
\end{tabular} & Boletus byo & Reputo & $18 \mathrm{HH} 0642559$ & 5811382 & VIII & Accilloso & \begin{tabular}{|l|l}
98 \\
\end{tabular} & \begin{tabular}{|l|l|} 
Bosque Nativo \\
\end{tabular} & Mayo & 2015 & Mexcha & $\mathrm{NE}$ & No existe & No & $\mathrm{M}$ \\
\hline Códiligo & Especie probabable & Sector & $\begin{array}{c}\text { Coordenadhs Gee } \\
\text { Latited }\end{array}$ & grraficteas & Regagín & Suelo & \begin{tabular}{|l|l|l|l|l|l|l} 
\\
\end{tabular} & Es pecie asociata & Mes Colecta & Año & 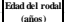 & Exposicíín & Densidad & Raleo & Tipo \\
\hline \begin{tabular}{|l|l|} 
IF865001 \\
\end{tabular} & Amanifa mistaria & Rafael & 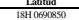 & $\frac{1 \text { Longuiutud }}{5935829}$ & VIII & \begin{tabular}{|l|} 
Limo arcilloso \\
\end{tabular} & 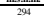 & Pinus radiata & Junio & 2015 & 15 & Plano & $\frac{(\text { artihlai) }}{4 \times 3}$ & Sisio & \\
\hline IF865002 & Russula sardonia & Rafael & $18 \mathrm{H} 06901850$ & 5935829 & VIII & Limo arcilloso & 294 & Pinus radiata & Janio & 2015 & 15 & Plano & $4 \times 3$ & $\mathrm{Si}$ & M \\
\hline IF865003 & willis littent & Rafael & 18406901850 & 5935829 & VIII & Limo arcilloso & 294 & Pinus radiata & Junio & 2015 & 15 & Plano & $4 \times 3$ & $\mathrm{Si}$ & $\mathrm{M}$ \\
\hline Códiligo & Es pecie probable & Sector & \begin{tabular}{|c|} 
Coordenadas Gee \\
\end{tabular} & graficas & Regáín & Suelo & \begin{tabular}{|l|l} 
Altitud \\
\end{tabular} & Especie asociada & Mes Colecta & Año & \begin{tabular}{|l|l|} 
Fihal del rodatal \\
\end{tabular} & Exposición & Densidad & Raleo o & Tipo \\
\hline IF866001 & Amanitur muscraria & Rafael-Coelemu & 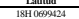 & 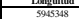 & VIII & \begin{tabular}{|l|} 
Limo arenoso \\
\end{tabular} & \begin{tabular}{|l|l|} 
ins.inin \\
234 \\
\end{tabular} & Pinus radiata & Junio & 2015 & $\frac{n}{10}$ & No & 203 & Shatiejo & $\mathrm{M}$ \\
\hline 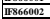 & Suillus tilters & RafaelCoelemum & 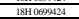 & 5945348 & $\mathrm{vil}$ & \begin{tabular}{|l|} 
Limo arenoso \\
\end{tabular} & 234 & \begin{tabular}{|l|l|l|l|l} 
Pinus radiatata \\
\end{tabular} & Junio & 2015 & 10 & No & 203 & no & $\mathrm{M}$ \\
\hline \begin{tabular}{|c|} 
Cóligo \\
\end{tabular} & Especie probabale & $\begin{array}{l}\text { Sector } \\
\end{array}$ & \begin{tabular}{|c|} 
Coordenadas $\mathrm{Gee}$ \\
Latitud \\
\end{tabular} & $\begin{array}{l}\text { grafificas } \\
\text { Longuitud }\end{array}$ & Regaín & Suelo & \begin{tabular}{|l|} 
Altitud \\
ms.n.n.
\end{tabular} & Especie asociadta & Mes Colecta & Año & \begin{tabular}{|c|}
$\begin{array}{c}\text { Fihal diel rodatal } \\
\text { (anhos) }\end{array}$ \\
\end{tabular} & Exposición & $\begin{array}{l}\text { Densidad } \\
\text { (arbhha) }\end{array}$ & $\begin{array}{l}\text { Raleo o } \\
\text { Manejo } \\
\end{array}$ & $\begin{array}{c}\text { Tipo } \\
\text { Hongo }\end{array}$ \\
\hline Ir867001 & Sullitus grandiatus & Coelemu & \begin{tabular}{|c|c|}
$18 \mathrm{H} 070366699$ \\
\end{tabular} & 59601648 & vill & \begin{tabular}{|l|l|} 
Limo arenoso \\
\end{tabular} & 29 & $\begin{array}{l}\text { Pinus radiata } \\
\end{array}$ & Junio & 2015 & 8 & NE & 233 & No & $\mathrm{M}$ \\
\hline$\sqrt{1 \times 867002}$ & $\begin{array}{l}\text { Suilhus thetens } \\
\end{array}$ & Coelemu & $\begin{array}{ll}18 H 0705669 \\
1400600\end{array}$ & $\frac{5961548}{506568}$ & VIII & \begin{tabular}{|l|l|} 
Lino arenoso \\
\end{tabular} & 29 & $\begin{array}{l}\text { Pinus radiata } \\
\text { Piow robiat }\end{array}$ & Junio & 2015 & 8 & NE & 23 & $\begin{array}{lll}\text { NO } \\
\text { No }\end{array}$ & $\mathrm{M}$ \\
\hline \begin{tabular}{|l}
1 I8867003 \\
\end{tabular} & Hebelonn crustulinitiforme & Coelemu & $18 \mathrm{H} 0005669$ & 5960648 & vill & \begin{tabular}{|l|} 
Limo arenoso \\
\end{tabular} & 29 & Pinus radiata & Janio & 2015 & 8 & NE & $2 \times 3$ & NO & $\mathrm{M}$ \\
\hline Cóxligo & Es pecie probable & Sector & \begin{tabular}{|c} 
Coordenadas $\mathrm{Gec}$ \\
Latitud \\
\end{tabular} & $\begin{array}{l}\text { grafificas } \\
\text { Longuitud }\end{array}$ & Regaín & Suelo & \begin{tabular}{|c|} 
Altitud \\
ms.n.n.
\end{tabular} & Especie asociada & Mes Colecta & Af̂̃o & 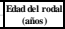 & Exposicíín & $\begin{array}{l}\text { Densidad } \\
\text { (arbhla) }\end{array}$ & $\begin{array}{l}\text { Raleo o } \\
\text { Manejo }\end{array}$ & $\begin{array}{l}\text { Tipo } \\
\text { Hongo }\end{array}$ \\
\hline $\begin{array}{ll}1 \text { II868001 } \\
\end{array}$ & Suillus granulatus & $\begin{array}{l}\text { Quirinue-Cauquenes } \\
\end{array}$ & $18 \mathrm{H} 07202026$ & 5987227 & VIII & \begin{tabular}{|l|} 
Arcillo Lmoso \\
\end{tabular} & 254 & Pinus radiata & Junio & 2015 & 7 & SE & $2 \times 3$ & No & $\mathrm{M}$ \\
\hline 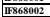 & Amanita Muscartia & Quirfhue-Cauquenes & $18 \mathrm{H} 02202026$ & 598727 & vil & \begin{tabular}{|l|} 
Arcillo Limoso \\
\end{tabular} & 254 & $\begin{array}{l}\text { Pinus radiata } \\
\end{array}$ & Janio & 2015 & 7 & SE & $2 \times 3$ & No & $\mathrm{M}$ \\
\hline 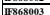 & 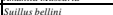 & Quinhue-Cauquenes & $\frac{18402020256}{1856}$ & $\frac{596727}{598727}$ & VIII & Arcillo limoso & 254 & Pinus radiata & Junio & 2015 & & SE & $2 \times 3$ & No & $\mathrm{M}$ \\
\hline Cónligo & \begin{tabular}{|l|l|} 
Especie probabable \\
\end{tabular} & Sector & \begin{tabular}{|c} 
Coordenatals $\mathrm{G}$ \\
Latitud \\
\end{tabular} & cas & Regín & Suelo & \begin{tabular}{|c|} 
Altitud \\
ms.n.nm
\end{tabular} & Eispecie asociata & Mes Colecta & Añó & \begin{tabular}{|c|}
$\begin{array}{c}\text { Fihad diel rodatal } \\
\text { (anhos) }\end{array}$ \\
(a)
\end{tabular} & Exposición & $\begin{array}{l}\text { Densidad } \\
\text { (arbh/ha) } \\
\text { (a) }\end{array}$ & $\begin{array}{l}\text { Raleo o } \\
\text { Manejo }\end{array}$ & $\begin{array}{c}\text { Tipo } \\
\text { Hongo }\end{array}$ \\
\hline II869001 & Pholiota. sp & San Pedro de la Paz & $18 \mathrm{H} 0668 \mathrm{6} 107$ & 5921372 & vill & madera & \begin{tabular}{|l}
11 \\
11
\end{tabular} & Betula sp & Janio & 2015 & \begin{tabular}{|l|} 
Aebolis solit. \\
\end{tabular} & Plano & 0 & $\frac{1}{0}$ & $\mathrm{~s}$ \\
\hline Cólizo & Especie probabile & Sector & \begin{tabular}{|c|} 
Coordenadas $\mathrm{Gec}$ \\
Latitud
\end{tabular} & graficas & Regáín & Suelo & \begin{tabular}{|l|} 
Altitud \\
ms num
\end{tabular} & Especie asociada & Mes Colecta & Ā̃o & 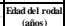 & Exposición & $\begin{array}{c}\text { Densidad } \\
\text { (arb/ha) }\end{array}$ & $\begin{array}{l}\text { Raleo o } \\
\text { Janejo }\end{array}$ & Tipo \\
\hline IF870001 & Morchella esculenta & Yumgay - Santa Lisisa & $19 \mathrm{H} 0261211$ & 5889946 & VIII & Trumao & \begin{tabular}{|l|l|}
8311 \\
\end{tabular} & \begin{tabular}{|l|} 
Bosque Nativo \\
\end{tabular} & \begin{tabular}{|l|} 
Novientbre \\
\end{tabular} & 2015 & Mercla & so & Mercla & No & $\mathrm{M}$ \\
\hline \begin{tabular}{|l|l|} 
IF870002 \\
\end{tabular} & Morchella elata & Yumgay - Santa Lisisa & $19 \mathrm{H} 12621211$ & 5889946 & VIII & Trumao & 831 & \begin{tabular}{|l|l|} 
Bosque Nativo \\
\end{tabular} & Novientbre & 2015 & Mercla & so & Mexcla & No & $\mathrm{M}$ \\
\hline \begin{tabular}{|l|l|} 
IF870003 \\
\end{tabular} & Morchella conica & $\begin{array}{l}\text { Yungay - Santa Luisa } \\
\end{array}$ & $19 \mathrm{H} 1261211$ & 5889946 & VIII & Trumao & 831 & \begin{tabular}{|l|l} 
Bosque Nativo \\
\end{tabular} & \begin{tabular}{|l|} 
Novientbre \\
\end{tabular} & 2015 & Mezcla & so & Mexcha & No & $\mathrm{M}$ \\
\hline \begin{tabular}{|l|l|} 
IF870004 \\
\end{tabular} & Gyromiltru escalients & Yungay - Santa Lisisa & $19 \mathrm{H} 0261211$ & 5889946 & $\mathrm{VIII}$ & Trumao & 831 & Bosque Nativo & \begin{tabular}{|l|} 
Novienbre \\
\end{tabular} & 2015 & $\mathrm{Me}$ & so & $\mathrm{Me}$ & № & $\mathrm{M}$ \\
\hline \begin{tabular}{|l|l|} 
II8770005 \\
\end{tabular} & CyHaria berteroi & & $19 \mathrm{H} 0261211$ & 5889946 & vill & $\begin{array}{l}\text { Trumao } \\
\end{array}$ & 831 & Bosque Nativo & \begin{tabular}{|l|} 
Noviembre \\
\end{tabular} & 2015 & Mercla & so & Mexcha & No & $\mathrm{M}$ \\
\hline Ciskigo & Es pecie probatile & Sector & Coordenadas Gec & grafificas & Regagín & Suelo & \begin{tabular}{|l|l|} 
Altitudud \\
\end{tabular} & Es pecie asociada & Mes Colecta & Año & 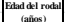 & Expasicíín & Densidad & Raleo & Tipo \\
\hline \begin{tabular}{|l|l|}
$1 \times 871001$ \\
\end{tabular} & \begin{tabular}{|l} 
Rhisopogon liteolus \\
.
\end{tabular} & Camino Haalhui & $\begin{array}{l}\text { Latitid } \\
18 \text { H0688288 }\end{array}$ & $\frac{\text { Longuiutud }}{5911599}$ & VIII & Arcillo arenoso & \begin{tabular}{|l|} 
m..nm \\
211 \\
\end{tabular} & Pinus radiata & Octubre & 2015 & \begin{tabular}{|l} 
(aunsi \\
\end{tabular} & NE & $\frac{\text { (arb/ha) }}{2.5 \times 2,5}$ & $\frac{\text { Manejo }}{\text { No }}$ & Hongo \\
\hline 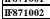 & \begin{tabular}{|l|l} 
Sullhus literus \\
\end{tabular} & Camino Hualqui & $18 \mathrm{H} 0688288$ & 5911599 & VIII & \begin{tabular}{|l} 
Arcillo arenoso \\
\end{tabular} & 211 & Pinus radiatata & Octubre & 2015 & 3 & $\mathrm{NE}$ & $2,5,0,5$ & No & $\mathrm{M}$ \\
\hline 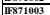 & 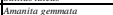 & Camino Hualqui & $18 \mathrm{H} 0688288$ & 5911599 & VIII & \begin{tabular}{|l} 
Arcillo arenoso \\
\end{tabular} & 211 & Pinus rudiata & Octubre & 2015 & 3 & NE & 2.50 .5 & No & $\mathrm{M}$ \\
\hline Cóliligo & Es pecie probabile & Sector & \begin{tabular}{|l} 
Coordenadas Gee \\
\end{tabular} & grrafifeas & Regíín & Suelo & \begin{tabular}{|l|l|l} 
Altitud \\
\end{tabular} & Especie asociada & Mes Colecta & Año & \begin{tabular}{|l|} 
Fihd del rodatal \\
\end{tabular} & Exposición & Densidad & Raleon & Tipo \\
\hline IF872001 & Suillus grantiatus & Camino Hualqui & $\frac{\text { Latitud }}{18 \mathrm{0} 6696933}$ & $\frac{\text { Longuiutud }}{591275}$ & VIII & Arrilloso & \begin{tabular}{|l|l|l|l} 
ins.inin \\
188
\end{tabular} & Pinus radiata & Octubre & 2015 & $\frac{\text { (athas) }}{12}$ & Plano & $\frac{\text { (arb/ha) }}{3 \times 3}$ & $\frac{\text { Saliejo }}{\text { No }}$ & $\frac{\text { Hongo }}{\mathrm{M}}$ \\
\hline \begin{tabular}{|l|} 
IF872002 \\
\end{tabular} & Amanita & Camino Hualqui & $18 \mathrm{H} 065956.33$ & 591275 & VIII & Arrilhso & 188 & Pinus radiata & Octubre & 2015 & 12 & Plano & 3.3 & No & $\mathrm{M}$ \\
\hline $\begin{array}{l}\text { Códilyo } \\
\end{array}$ & Ekpecie probabahle & Sector & \begin{tabular}{|l|} 
Coordenadas Gec \\
\end{tabular} & grafifcas & Regalín & Suelo & \begin{tabular}{|l|} 
Altitud \\
\end{tabular} & Especie associatata & Mes Colecta & Â̆ & \begin{tabular}{|l|} 
Fihal del rotatal \\
\end{tabular} & Exposicíín & Densitad & Raleo o & Tipo \\
\hline & & & Latitud & Longuitud & & & $\begin{array}{l}\text { ms.nm } \\
\end{array}$ & & & & (ahas) & & $\begin{array}{l}\text { (arbha) } \\
\text { (ark }\end{array}$ & Manejo & Hongo \\
\hline \begin{tabular}{|l|l|} 
F8873001 \\
\end{tabular} & Morchellasp & $\begin{array}{l}\text { Pasado Campanario } \\
\end{array}$ & $18 \mathrm{H} 0533063$ & 58856012 & VIIII & Arenoso & 2007 & Pinus radiata & Octubre & 2015 & 10 & $\begin{array}{l}\text { Plano } \\
\end{array}$ & & No & M \\
\hline II873002 & Amanita gemmata & Pasado Campananatio & $18 \mathrm{H} 0553063$ & 58856012 & vill & Arenoso & 2077 & $\begin{array}{l}\text { Pinus radiata } \\
\end{array}$ & Octubre & 2015 & 10 & Plano & $3 \times 3$ & No & $\mathrm{M}$ \\
\hline $\begin{array}{l}\text { II8773003 } \\
\end{array}$ & \begin{tabular}{|l} 
Suillus thaters \\
\end{tabular} & $\begin{array}{l}\text { Pasado Campanario } \\
\end{array}$ & \begin{tabular}{|l}
$18 \mathrm{H} 0753063$ \\
\end{tabular} & 58856012 & VIII & $\begin{array}{l}\text { Arenoso } \\
\end{array}$ & 2007 & \begin{tabular}{|c|} 
Pinus radiatata \\
\end{tabular} & Octubre & 2015 & 10 & Plano & $3 \times 3$ & No & $\mathrm{M}$ \\
\hline Coxiligo & Es pecie probabable & Sector & Caordenadas Gec & grrafifcas & Regsión & Suelo & \begin{tabular}{|c|c|} 
Altitudud \\
\end{tabular} & Es pecie asociata & \begin{tabular}{|l|} 
Mes Colecta \\
\end{tabular} & Afío & 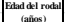 & Exposicición & Densidad & Raleos & Tipo \\
\hline II874001 & $s_{u}$ & $\mathrm{C}$ & & $\frac{\text { Longuifud }}{587079}$ & $\mathrm{VIII}$ & $\mathrm{A}$ & \begin{tabular}{|l|l|} 
mins.t.unt \\
320
\end{tabular} & & $\mathrm{Oc}$ & 2015 & (alubs) & Plano & $\frac{\operatorname{car}}{23}$ & Manejo & Hongo \\
\hline$\frac{11647001}{11584002}$ & 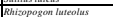 & Camino Tucapel Curva & $\frac{19403237945}{1945}$ & 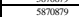 & VIII & Arenososo & $\frac{320}{320}$ & 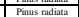 & $\begin{array}{l}\text { Oetuble } \\
\text { Octubre }\end{array}$ & $\frac{2013}{2015}$ & 13 & $\begin{array}{l}\text { Pradur } \\
\text { Plano }\end{array}$ & $2.5 \times 3$ & No & $\frac{M}{M}$ \\
\hline Cixilgo & Es pecie probablie & Sector & \begin{tabular}{|l|} 
Coordenahas $\mathrm{Gec}$ \\
\end{tabular} & tone & Regaíín & Suelo & \begin{tabular}{|l|l|l|l} 
Altitud \\
\end{tabular} & Especie asociada & Mes Colecta & Año & \begin{tabular}{|c|} 
Fihad del robatal \\
\end{tabular} & Exposicíín & Densidad & Raleo o & Tipo \\
\hline $\begin{array}{l}\text { II875001 } \\
\end{array}$ & Coprints conatus & Camino Antuco & $\frac{\text { Latuda }}{19 \mathrm{H} 0239066}$ & $\begin{array}{l}\text { Longinutua } \\
5873258\end{array}$ & VIII & Trumao & \begin{tabular}{|l|} 
ins.nint \\
321 \\
\end{tabular} & Pradera & Octubre & 2015 & $\frac{1}{0}$ & Plano & 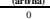 & $\frac{\text { Mantejo }}{\mathrm{No}}$ & Hoing \\
\hline IF875002 & Morchella sp & Camino Antuco & $19 \mathrm{H} 0237906$ & 58773528 & VIII & Trumao & 321 & Bosque Nativo & Octubre & 2015 & Mexcla & Plano & 0 & No & $M$ \\
\hline Cóxilgo & \begin{tabular}{|l} 
Es pecie probabahle \\
\end{tabular} & Sector & \begin{tabular}{|c|} 
Choordenaidas Gee \\
\end{tabular} & graificas & Regigín & Suelo & \begin{tabular}{|l|l} 
Alfitudud \\
\end{tabular} & Eispecie asociada & Mes Colecta & Aĭo & \begin{tabular}{|c|} 
Fihad diel rodatal \\
\end{tabular} & Exposición & Densidad & Raleo o & Tipo \\
\hline & & & Latitud & Longuitud & & & ms.s.m. & & & & (añss) & & (arb/ha) & Manejo & Hongo \\
\hline IF876001 & $M_{0}$ & Lateral Antuco & $19 \mathrm{H} 0261612$ & 5864407 & $\mathrm{VIII}$ & Trumaa & \begin{tabular}{|l}
688 \\
\end{tabular} & Bosque Nativo & Octubre & 2015 & Mercla & so & Mercla & No & M \\
\hline Cíxiligo & Es pecie probable & Sector & \begin{tabular}{|c} 
Coordenadas $\mathrm{Gec}$ \\
Latitud \\
\end{tabular} & grafificas & Reģión & Suelo & \begin{tabular}{|c|} 
Altitud \\
ms.n.n.
\end{tabular} & Especie asociada & \begin{tabular}{|c|} 
Mes Colecta \\
\end{tabular} & Año & 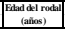 & Exposicíón & $\begin{array}{l}\text { Densidad } \\
\text { (arbhla) } \\
\text { (a) }\end{array}$ & $\begin{array}{l}\text { Raleo o } \\
\text { Manejo }\end{array}$ & $\begin{array}{c}\text { Tipo } \\
\text { Hongo }\end{array}$ \\
\hline \begin{tabular}{|l|}
$1 F 877001$ \\
15877002
\end{tabular} & 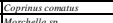 & $\begin{array}{l}\text { Final Camino } \\
\text { FinalCmino }\end{array}$ & \begin{tabular}{|c|}
$19 \mathrm{H} 0261612$ \\
\end{tabular} & $\frac{368+407}{586407}$ & $\begin{array}{l}\mathrm{vIII} \\
\mathrm{y} / \mathrm{II}\end{array}$ & $\begin{array}{l}\text { Trumao } \\
\text { Trumas }\end{array}$ & 688 & \begin{tabular}{|l|} 
Bosque Nativo \\
\end{tabular} & $\begin{array}{l}\text { Octubre } \\
\text { Octubrer }\end{array}$ & 2015 & Mercla & so & Mercla & $\frac{\mathrm{N} o}{\mathrm{~N}_{0}}$ & $\frac{s}{y}$ \\
\hline
\end{tabular}




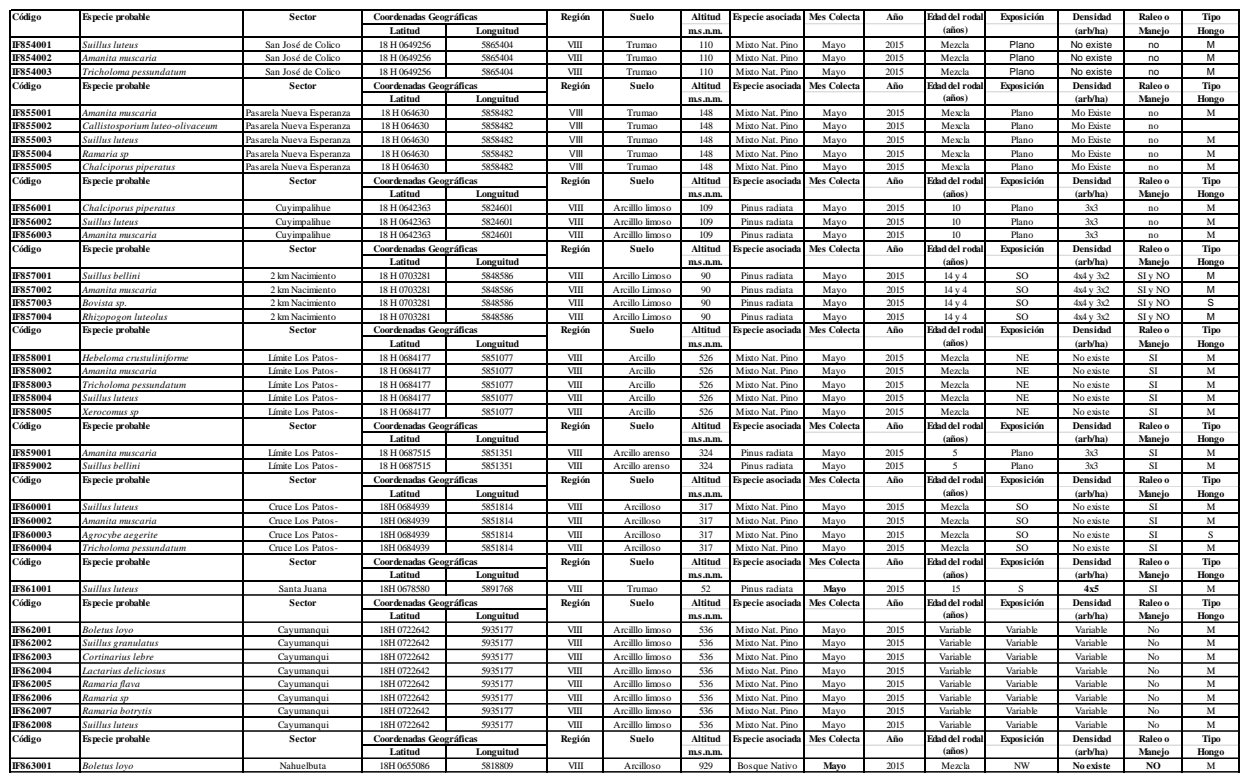




\section{ANEXO 3}

\section{Fotografías de Cepas Colectada en las Regiones de Maule y Bio Bio}

\section{Especie Probable y Código}

\section{Región del Maule}

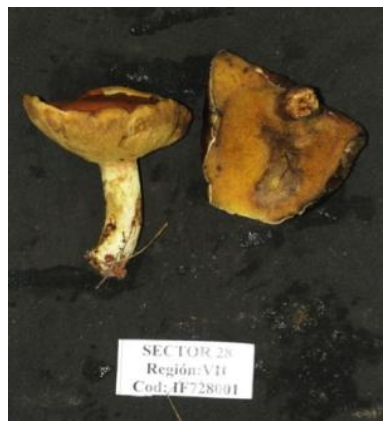

Especie Probable: Suillus granulatus Código: IF728001

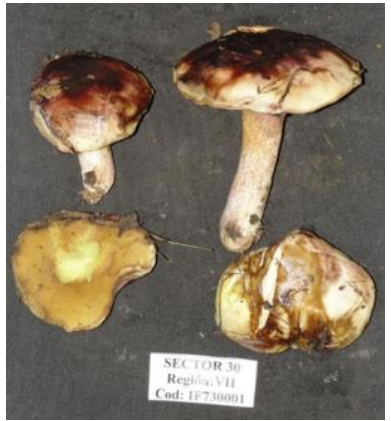

Especie Probable: Suillus bellini Código: IF730001

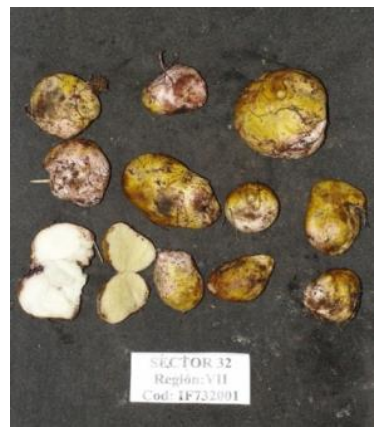

Especie Probable: Rhizopogon luteolus Código: IF732001

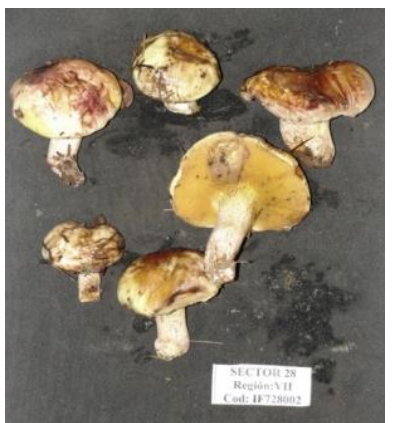

Especie Probable: Suillus bellini Código: IF728002

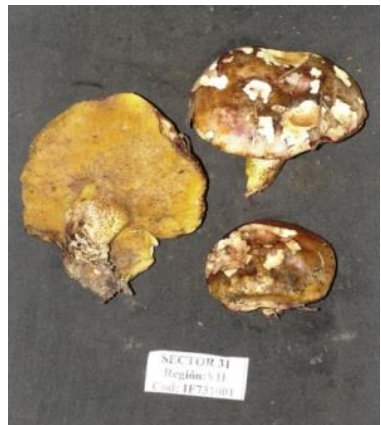

Especie Probable: Suillus bellini Código: IF731001

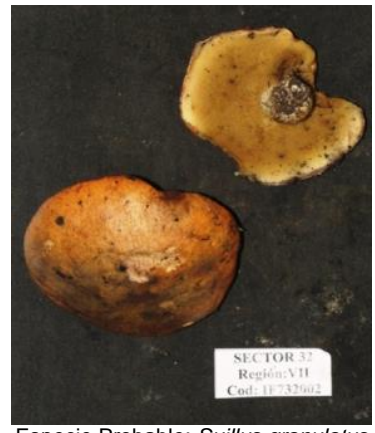

Especie Probable: Suillus granulatus Código: IF732002

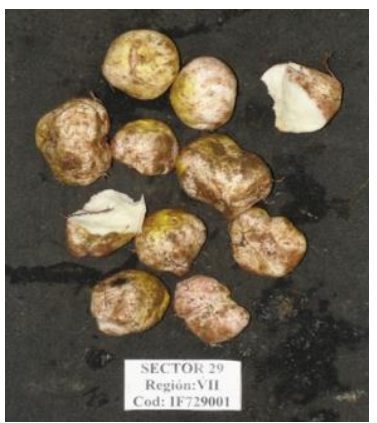

Especie Probable: Rhizopogon luteolus Código: IF729001

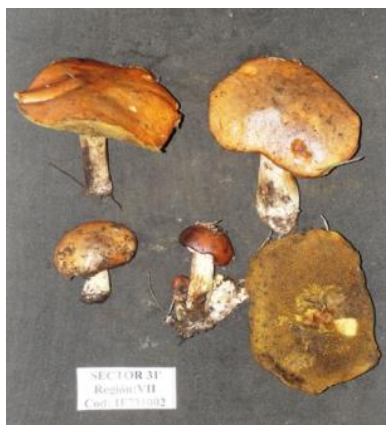

Especie Probable: Suillus granulatus Código: IF731002

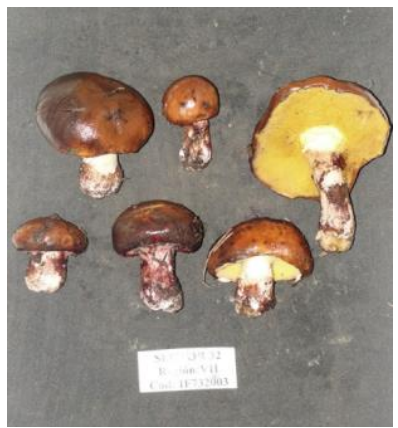

Especie Probable: Suillus luteus Código: IF732003 


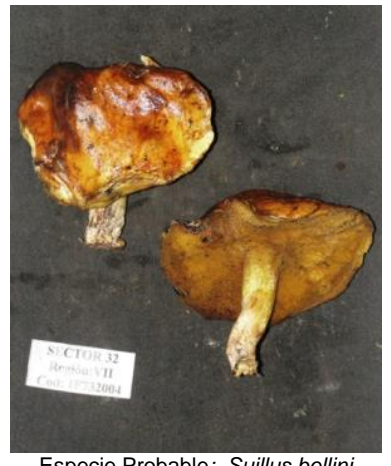

Especie Probable: Suillus bellini Código: IF732004

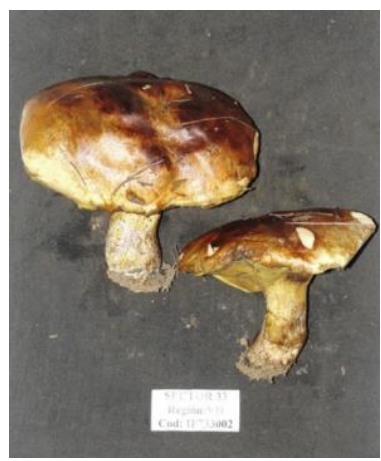

Especie Probable: Suillus bellini Código: IF733002

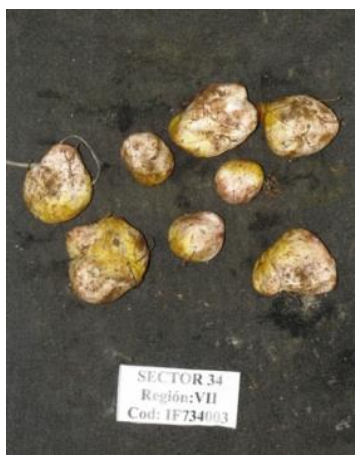

Especie Probable: Rhizopogon luteolus

Código: IF734003

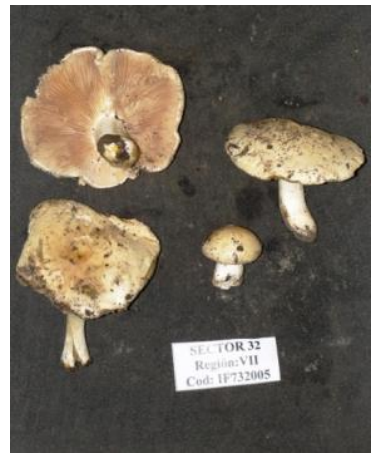

Especie Probable: Hebeloma crustuliniforme Código: IF732005

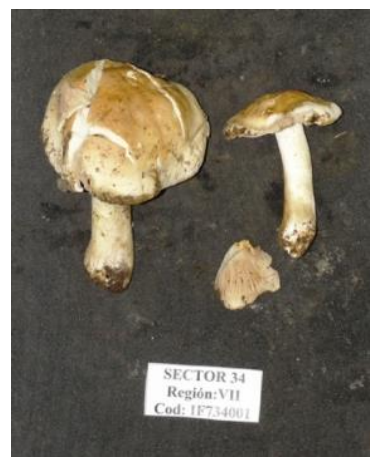

Especie Probable: Hebeloma crustuliniforme Código: IF734001

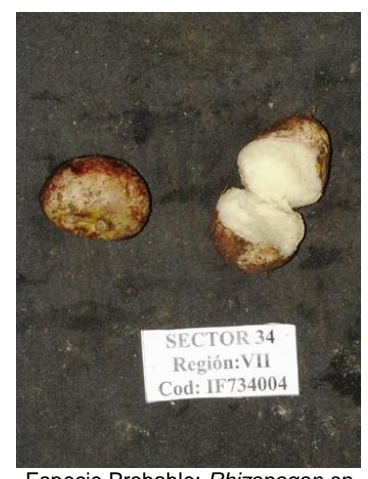

Especie Probable: Rhizopogon sp Código: IF734004

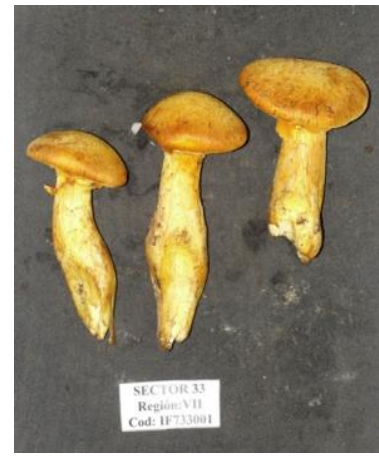

Especie Probable: Gymnopillus spectabilis Código: IF733001

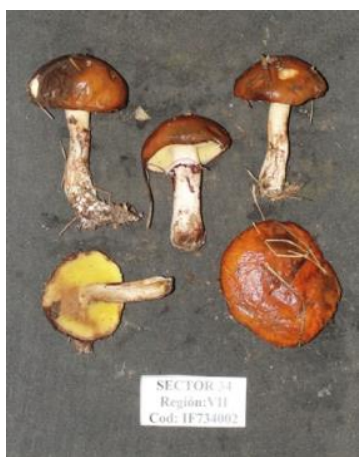

Especie Probable: Suillus luteus Código: IF734002

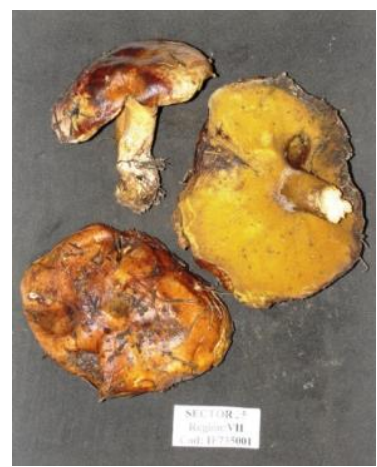

Especie Probable: Suillus bellini Código: IF735001 


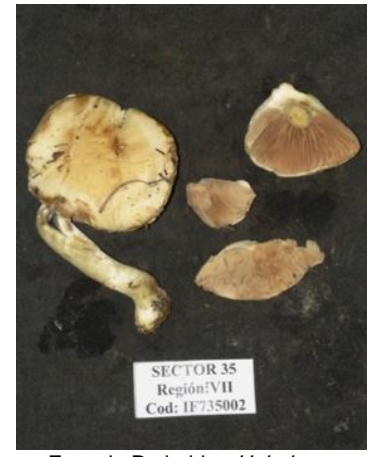

Especie Probable: Hebeloma

crustuliniforme

Código: IF735002

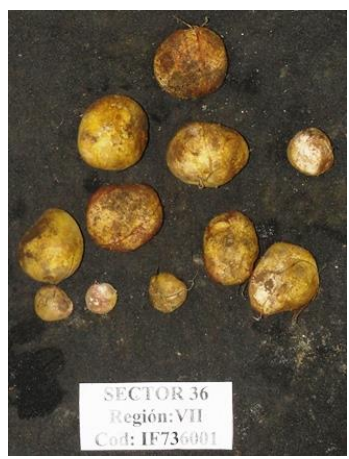

Especie Probable: Rhizopogon luteolus

Código: IF736001

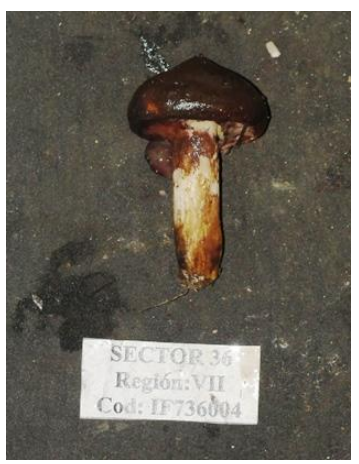

Especie Probable: Suillus luteus Código: IF736004

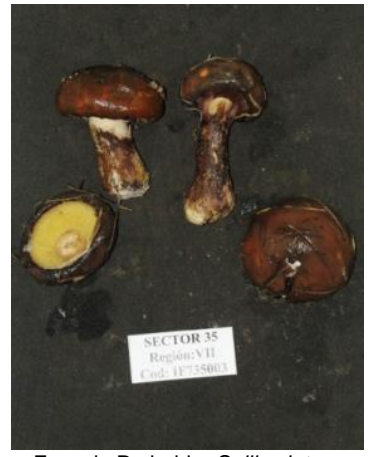

Especie Probable: Suillus luteus Código: IF735003

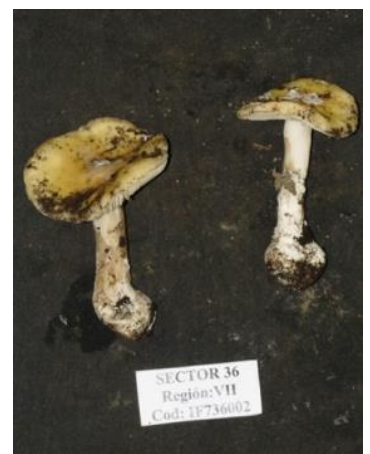

Especie Probable: Amanita gemmata Código: IF736002

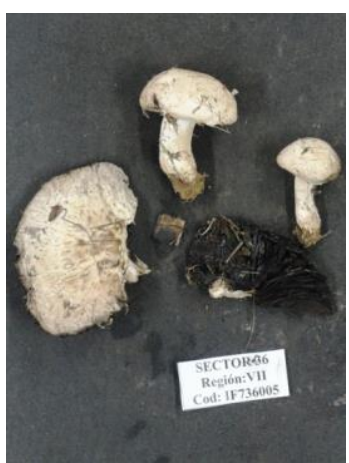

Especie Probable: Agaricus campestris Código: IF736005

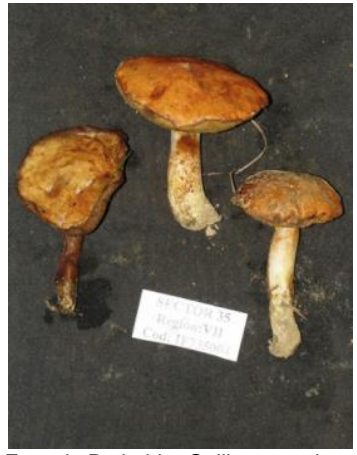

Especie Probable: Suillus granulatus Código: IF735004

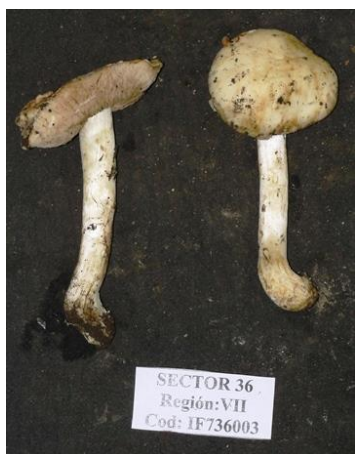

Especie Probable: Hebeloma crustuliniforme Código: IF736003

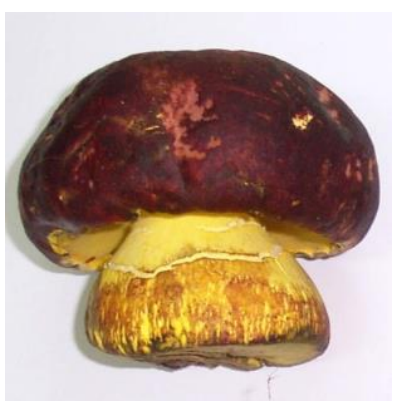

Especie Probable: Boletus loyo Código: IF737001 


\section{Región del Bio Bio}

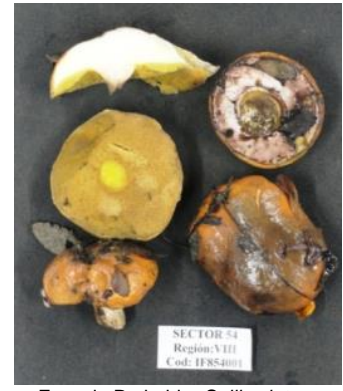

Especie Probable: Suillus luteus Código: IF854001

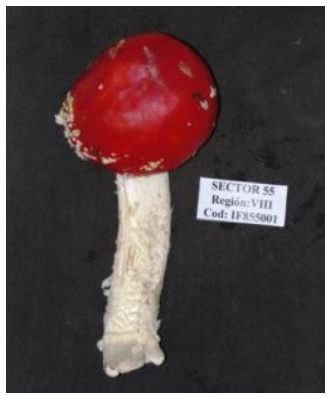

Especie Probable: : Amanita muscaria Código: IF855001

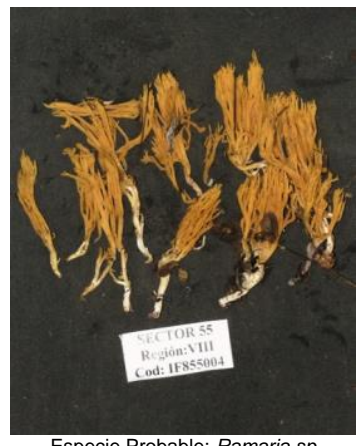

Especie Probable: Ramaria sp Código: IF855004

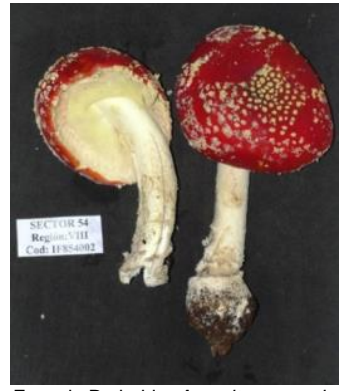

Especie Probable: Amanita muscaria Código: IF854002

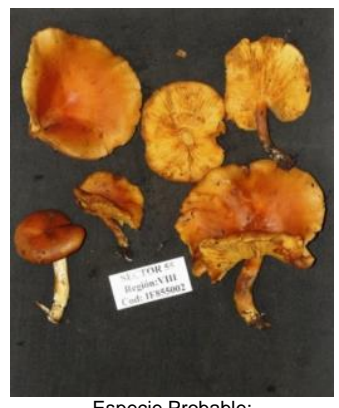

Especie Probable: Código: IF855002

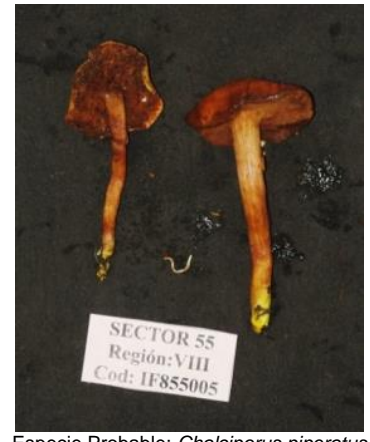

Especie Probable: Chalciporus piperatus Código: IF855005

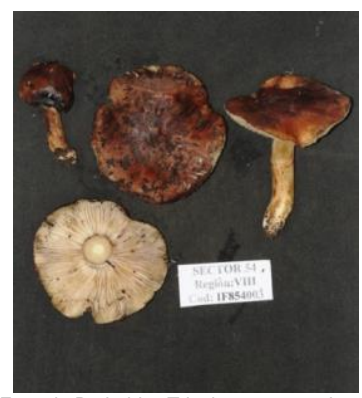

Especie Probable: Tricoloma pessundatum Código: IF854003

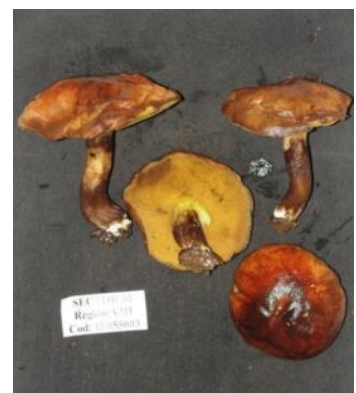

Especie Probable: Suillus luteus Código: IF855003

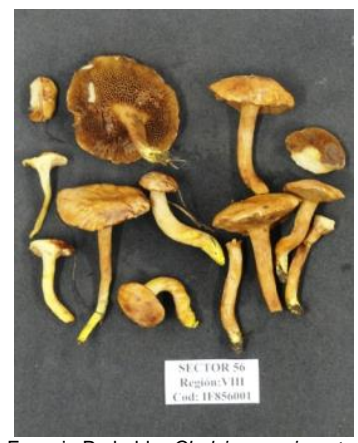

Especie Probable: Chalciporus piperatus Código: IF856001 


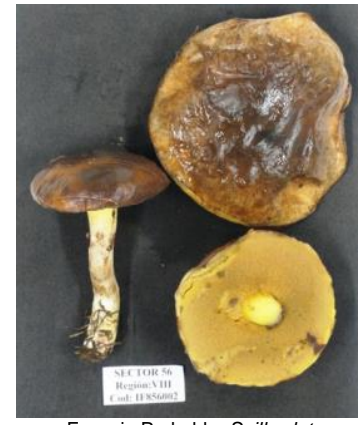

Especie Probable: Suillus luteus Código: IF856002

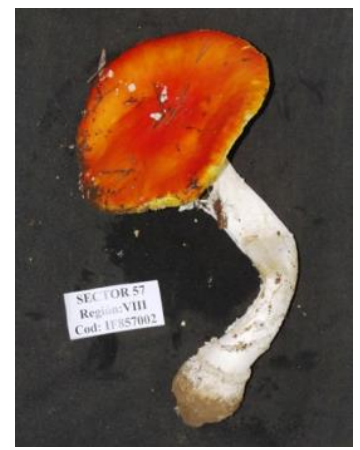

Especie Probable: Amanita muscaria Código: IF857002

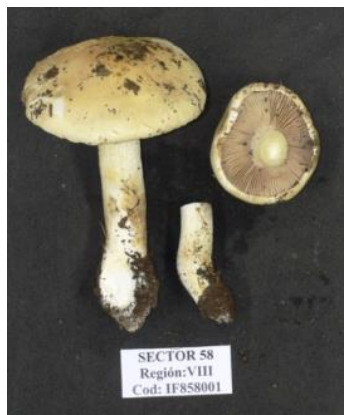

Especie Probable: Hebeloma crustuliniforme Código: IF858001

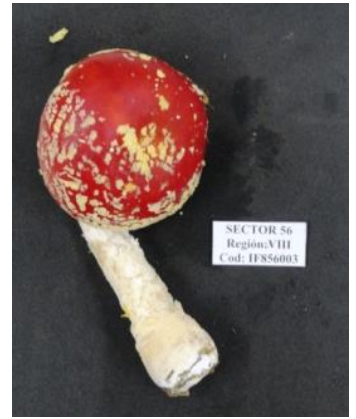

Especie Probable: Amanita muscaria Código: IF856003

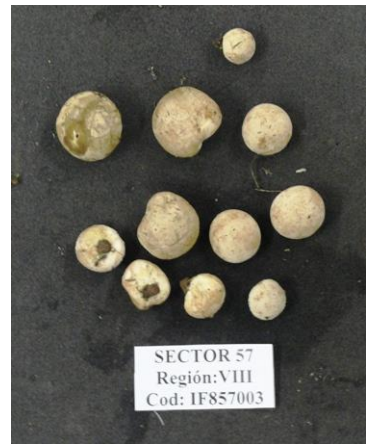

Especie Probable: Bovista sp Código: IF857003

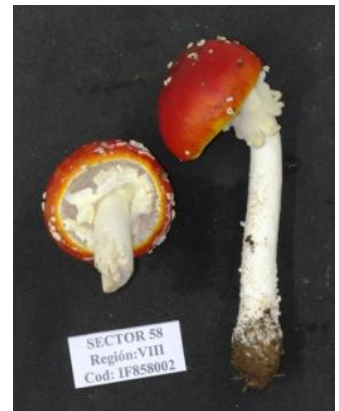

Especie Probable: Amanita muscaria Código: IF858002

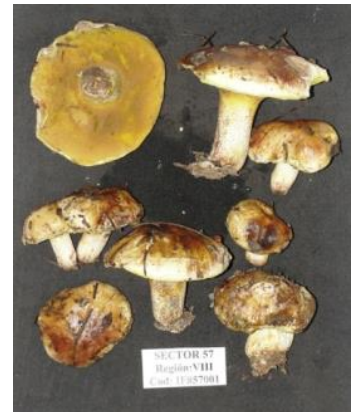

Especie Probable: Suillus bellini Código: IF857001

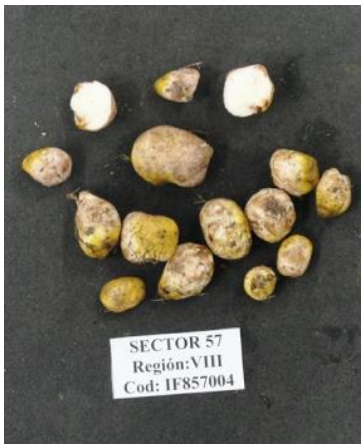

Especie Probable: Rhizopogon luteolus Código: IF857004

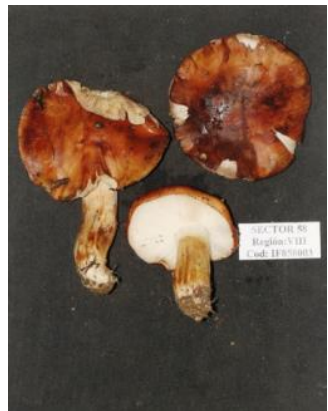

Especie Probable: Tricholoma pessundatum Código: IF858003 


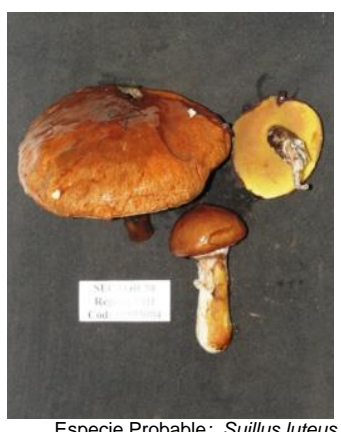

Especie Probable: Suillus luteus Código: IF858004

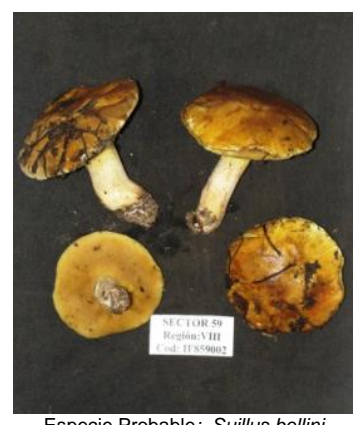

Especie Probable: Suillus bellini Código: IF859002

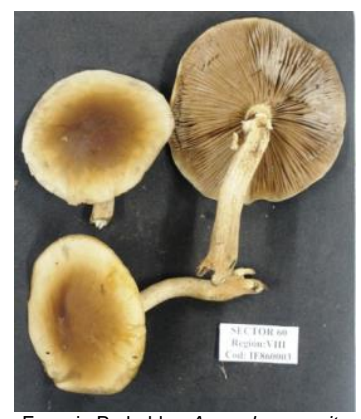

Especie Probable: Agrocybe aegerite Código: IF860003

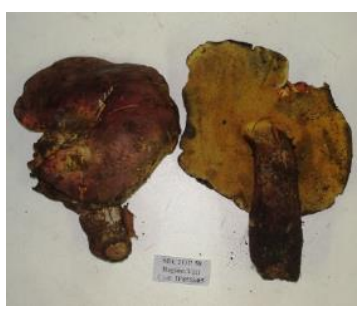

Especie Probable: Boletus loyita Código: IF858005

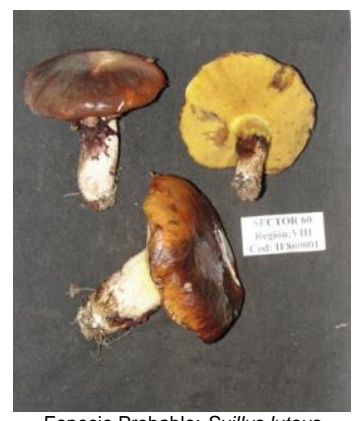

Especie Probable: Suillus luteus Código: IF860001

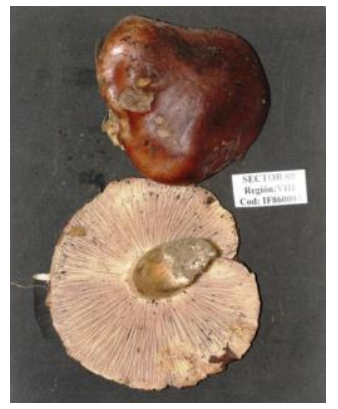

Especie Probable: Tricholoma pessundatum Código: IF860004

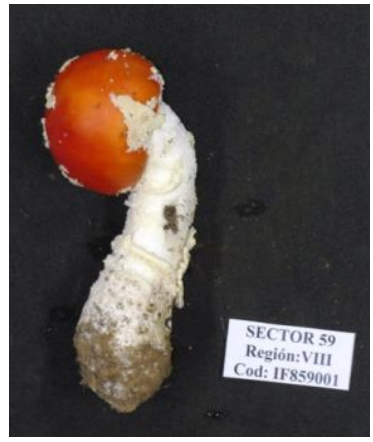

Especie Probable: Amanita muscaria Código: IF859001

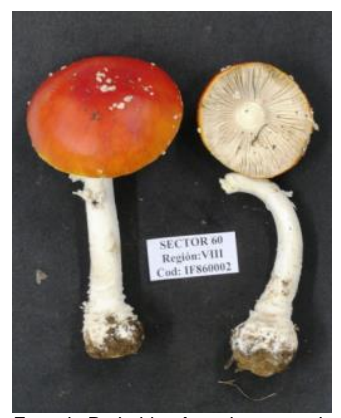

Especie Probable: Amanita muscaria Código: IF860002

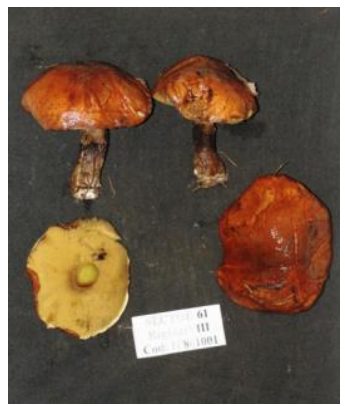

Especie Probable: Suillus luteus Código: IF861001 


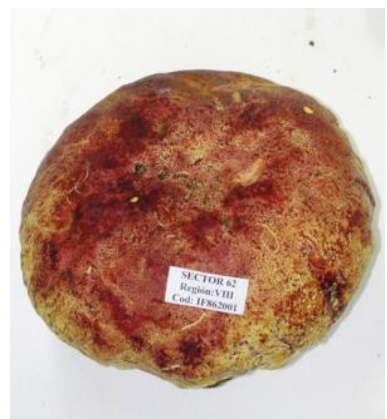

Especie Probable: Boletus loyo Código: IF862001

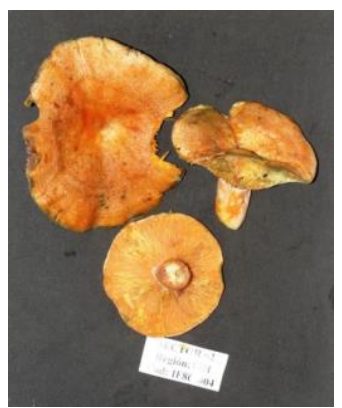

Especie Probable: Lactarius deliciosus Código: IF862004

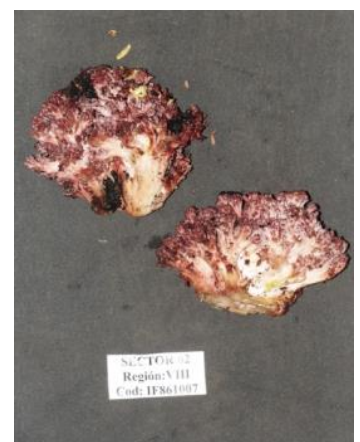

Especie Probable: Ramaria botrytis Código: IF862007

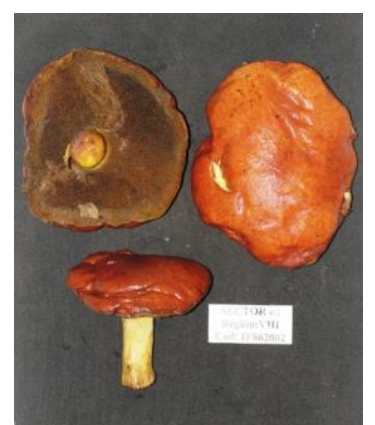

Especie Probable: Suillus granulatus Código: IF862002

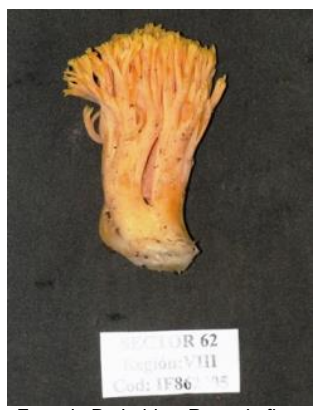

Especie Probable: Ramaria flava Código: IF862005

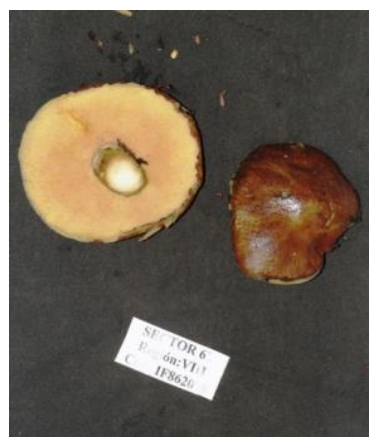

Especie Probable: Suiilus luteus Código: IF862008

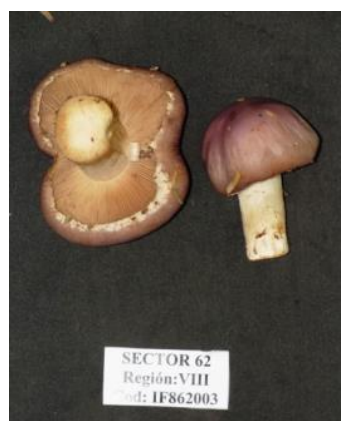

Especie Probable: Cortinarius lebre Código: IF862003

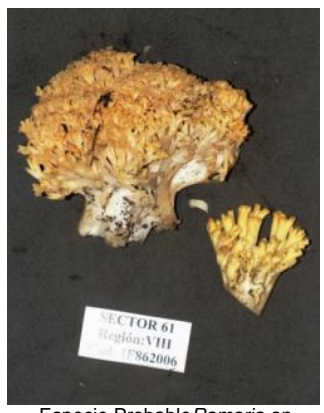

Especie Probable Ramaria sp Código: IF862006

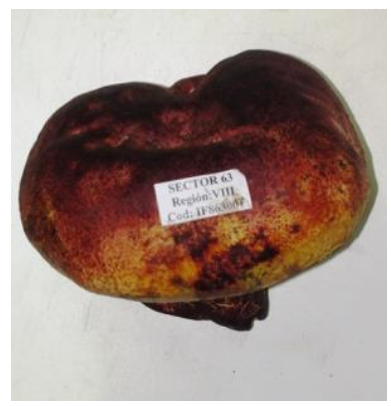

Especie Probable: Boletus loyo Código: IF86300 


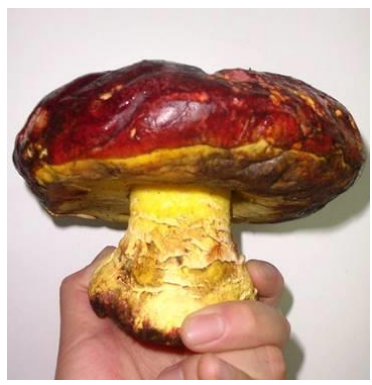

Especie Probable: Boletus loyo Código: IF864001

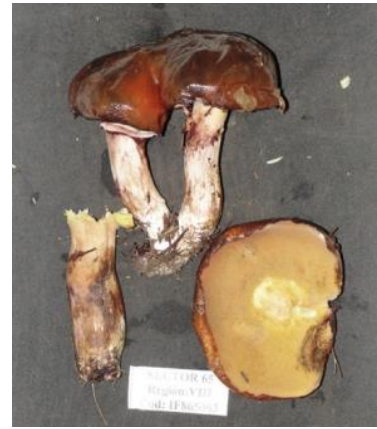

Especie Probable: Suillus luteus Código: IF865003

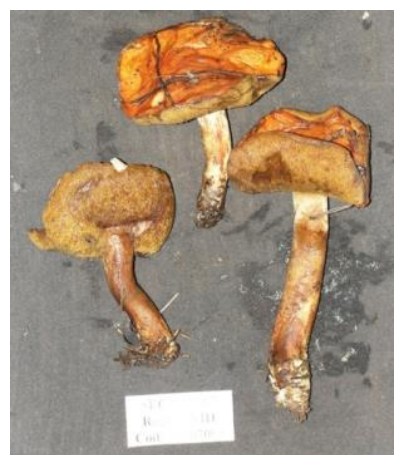

Especie Probable: Suillus granulatus Código: IF867001

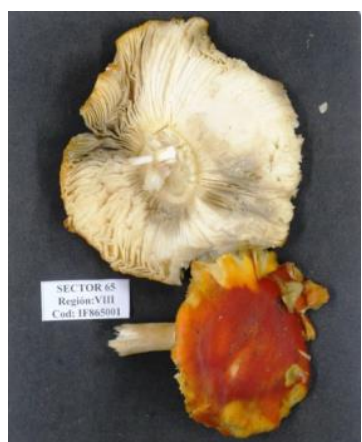

Especie Probable: Amanita muscaria Código: IF865001

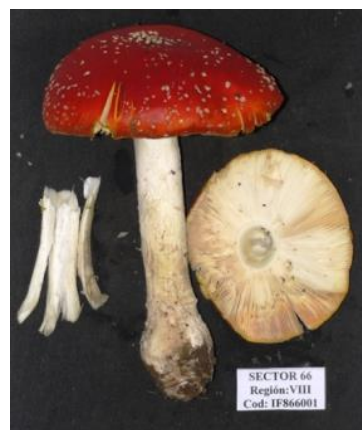

Especie Probable: Amanita muscaria Código: IF866001

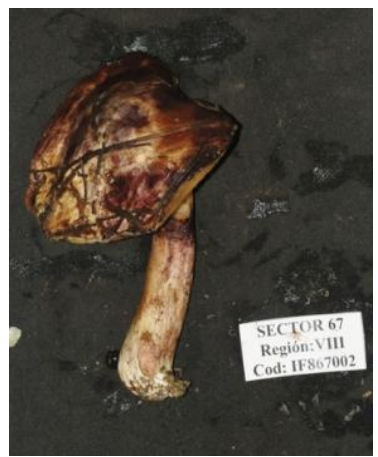

Especie Probable: Suillus luteus Código: IF867002

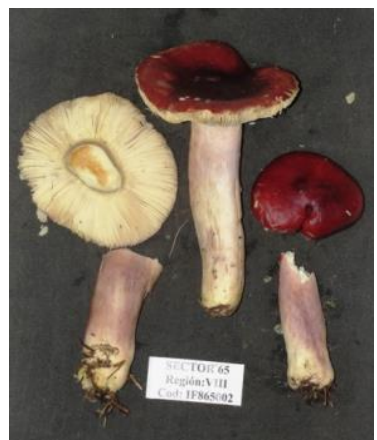

Especie Probable: Russula sardonia Código: IF865002

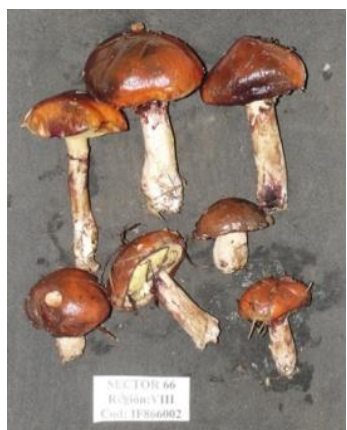

Especie Probable: Suilus luteus Código: IF866002

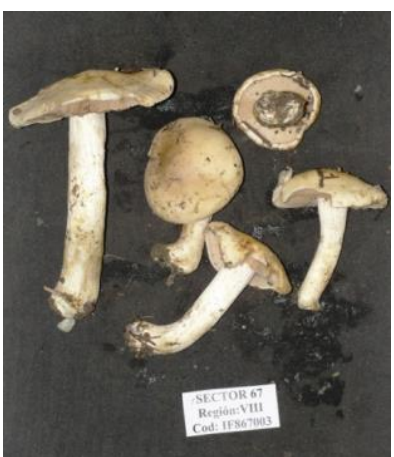

Especie Probable: Hebeloma crustuliniforme Código: IF867003 


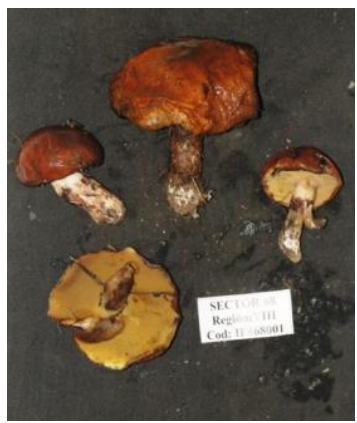

Especie Probable: Suillus luteus Código: IF868001

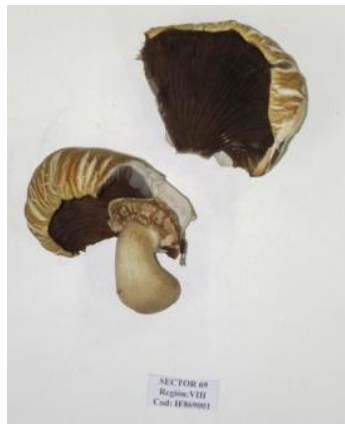

Especie Probable: Agrocybe aegerita Código: IF869001

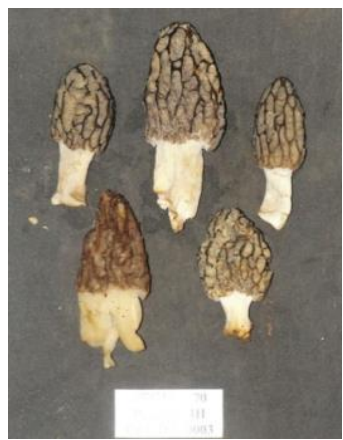

Especie Probable: Morchella conica Código: IF870003

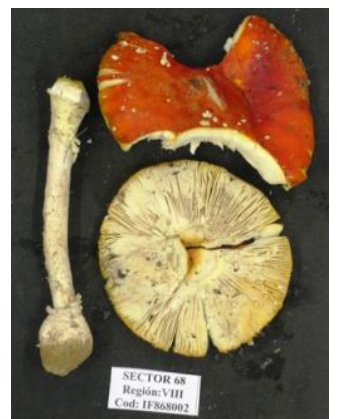

Especie Probable: Amanita muscaria Código: IF868002

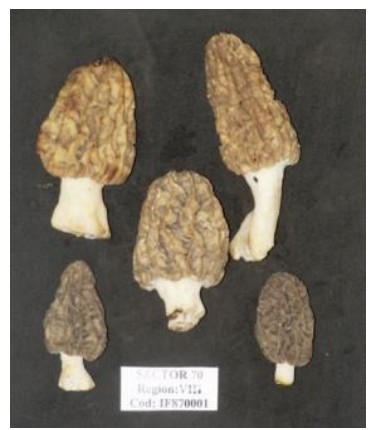

Especie Probable: Morchella esculenta Código: IF870001

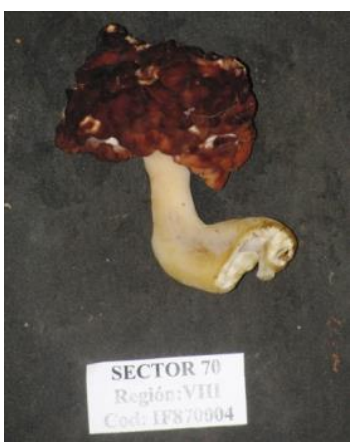

Especie Probable: Gyromitra esculenta Código: IF870004

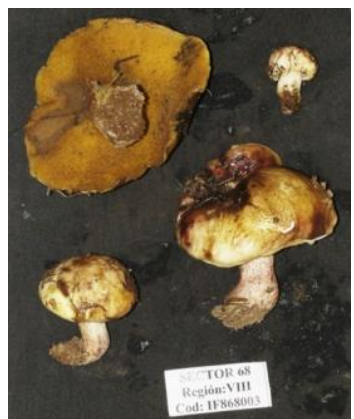

Especie Probable: Suillus bellin Código: IF868003

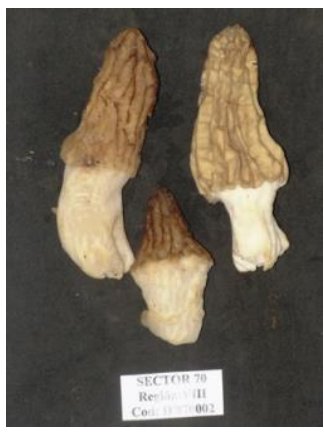

Especie Probable: Morchella elata Código: IF870002

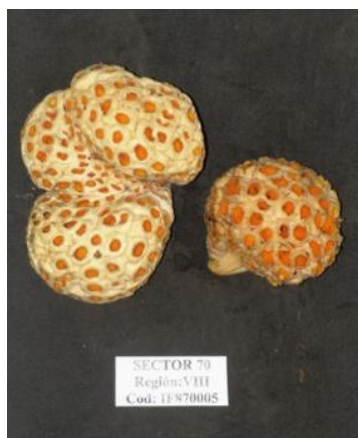

Especie Probable: Cyttaria berteroi Código: IF870005 


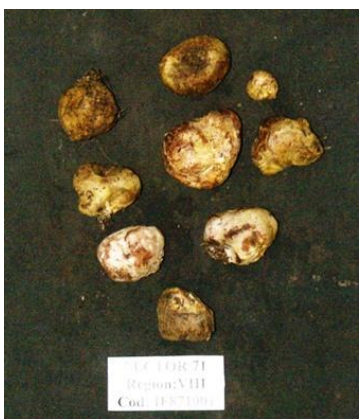

Especie Probable: Rhizopogon roseolus Código: IF871001

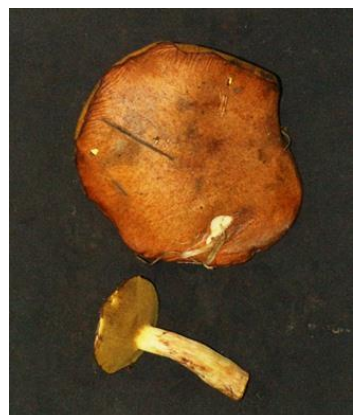

Especie Probable: Suillus granulatus Código: IF872001

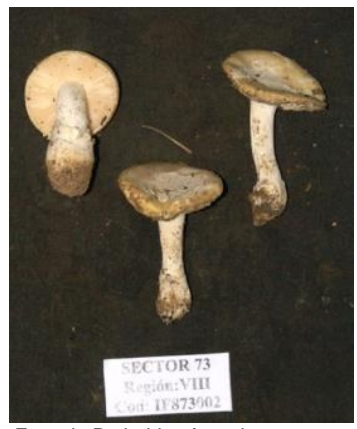

Especie Probable: Amanita gemmata Código: IF873002

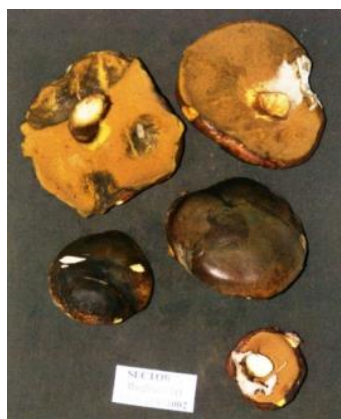

Especie Probable: Suillus luteus Código: IF871002

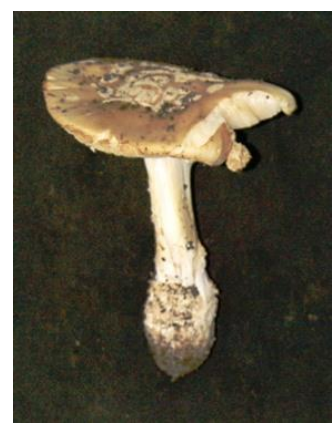

Especie Probable: Amanita gemmata Código: IF872002

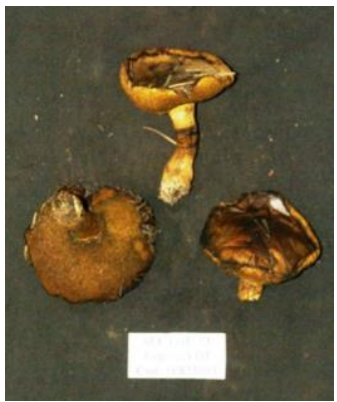

Especie Probable: Suillus luteus Código: IF873003

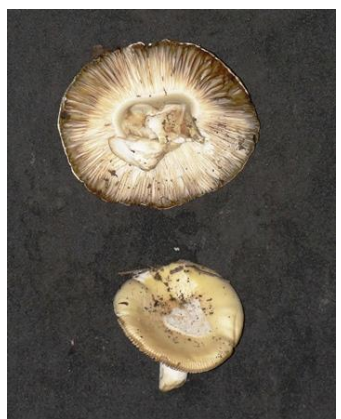

Especie Probable: Amanita gemmata Código: IF871003

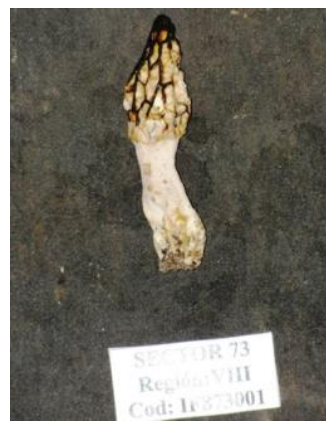

Especie Probable: Morchella elata Código: IF873001

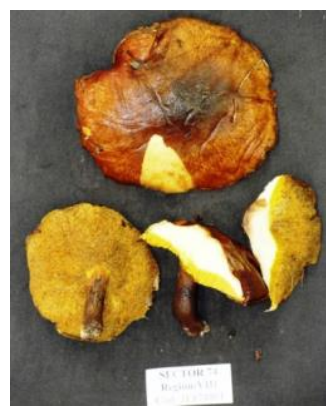

Especie Probable: Suillus luteus Código: IF874001 


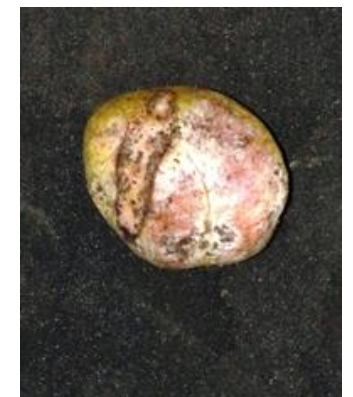

Especie Probable: Rhizopogon luteolus Código: IF874002

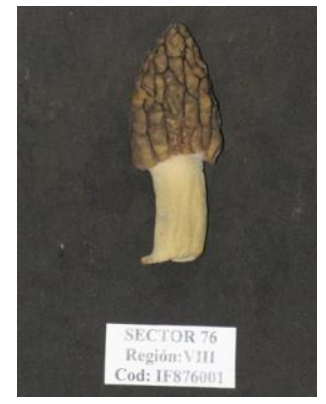

Especie Probable: Morchella conica Código: IF876001

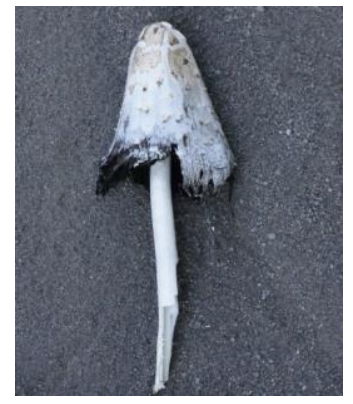

Especie Probable: Coprinus comatus Código: IF875001

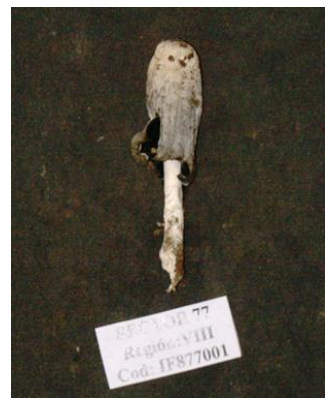

Especie Probable: Coprinus comatus Código: IF877001

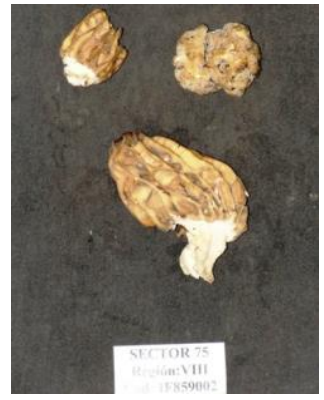

Especie Probable: Morchella esculenta Código: IF875002

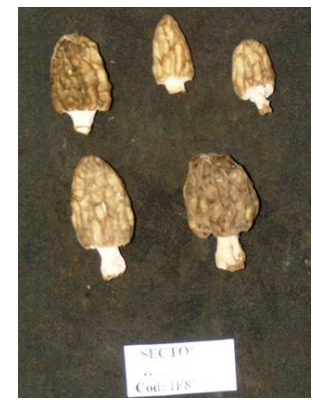

Especie Probable: Morchella esculenta Código: IF877002 


\section{ANEXO 4}

\section{Formulario de Medición del Crecimiento Radial}

INSTITUTO FORESTAL

Hoja $\mathbf{N}^{\circ}$ :

\begin{tabular}{|c|c|c|c|c|c|c|c|c|c|c|c|c|c|}
\hline \multirow{2}{*}{$\begin{array}{c}\text { CÓDIGO } \\
\text { CEPA }\end{array}$} & \multirow{2}{*}{$\begin{array}{c}\text { MEDIO DE } \\
\text { CULTIVO }\end{array}$} & \multicolumn{4}{|c|}{ Disco Petri 1} & \multicolumn{4}{|c|}{ Disco Petri 2} & \multicolumn{4}{|c|}{ Disco Petri 3} \\
\hline & & $\begin{array}{c}\text { Crec. } \\
\text { Radial } 1\end{array}$ & $\begin{array}{c}\text { Crec. } \\
\text { Radial } 2\end{array}$ & $\begin{array}{c}\text { Crec. } \\
\text { Radial } 3\end{array}$ & $\begin{array}{c}\text { Crec. } \\
\text { Radial } 4\end{array}$ & $\begin{array}{c}\text { Crec. } \\
\text { Radial } 1\end{array}$ & $\begin{array}{c}\text { Crec. } \\
\text { Radial } 2 \\
\end{array}$ & $\begin{array}{c}\text { Crec. } \\
\text { Radial } 3 \\
\end{array}$ & $\begin{array}{c}\text { Crec. } \\
\text { Radial } 4\end{array}$ & $\begin{array}{c}\text { Crec. } \\
\text { Radial } 1\end{array}$ & $\begin{array}{c}\text { Crec. } \\
\text { Radial } 2\end{array}$ & $\begin{array}{c}\text { Crec. } \\
\text { Radial } 3\end{array}$ & $\begin{array}{c}\text { Crec. } \\
\text { Radial } 4 \\
\end{array}$ \\
\hline & PDA & & & & & & & & & & & & \\
\hline & MMN & & & & & & & & & & & & \\
\hline & BAF & & & & & & & & & & 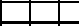 & 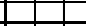 & 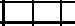 \\
\hline & PDA & & & & & & & & & & & & \\
\hline & MMN & & & & & & & & & & & 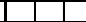 & \\
\hline & BAF & & & & & & & & & & & 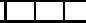 & \\
\hline & PDA & & & & & & & & & & & & \\
\hline & MMN & & & & & & & & & & & & \\
\hline & BAF & & & & & & & & & & & 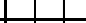 & \\
\hline & PDA & & & & & & & & & & & 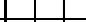 & \\
\hline & MMN & & & & & & & & & & & 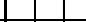 & \\
\hline & BAF & & & & & & & & & & & 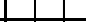 & \\
\hline & PDA & & & & & & & & & & & 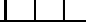 & \\
\hline & MMN & & & & & & & & & & & 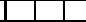 & \\
\hline & BAF & & & & & & & & & & & 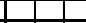 & \\
\hline & PDA & & & & & & & & & & & & \\
\hline & MMN & & & & & & & & & & & & \\
\hline & BAF & & & & & & & & & & & & \\
\hline & PDA & & & & & & & & & & & & \\
\hline & MMN & & & & & & & & & & & & \\
\hline & BAF & & & & & & & & & & & & \\
\hline & PDA & & & & & & & & & & & & \\
\hline & MMN & & & & & & & & & & & - & \\
\hline & BAF & & & & & & & & & & & & \\
\hline & PDA & & & & & & & & & & & 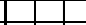 & \\
\hline & MMN & & & & & & & & & & & & \\
\hline & BAF & & & & & & & & & & & 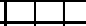 & \\
\hline & PDA & & & & & & & & & & & & \\
\hline & MMN & & & & & & & & & & & & \\
\hline & BAF & & & & & & & & & & & & \\
\hline & PDA & & & & & & & & & & & & \\
\hline & MMN & & & & & & & & & & & 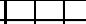 & \\
\hline & BAF & & & & & & & & & & & & \\
\hline & PDA & & & & & & & & & & & & \\
\hline & MMN & & & & & & & & & & & & \\
\hline & BAF & & & & & 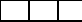 & & & & & & & \\
\hline & PDA & & & & & & & & & & & & \\
\hline & MMN & & & & & & & & & & 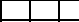 & - & \\
\hline & BAF & & & & & & & & & & & 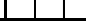 & \\
\hline
\end{tabular}


